\title{
Derechos Económicos Sociales y \\ Culturales de los Pueblos Indígenas \\ y su relación con las reivindicaciones \\ Territoriales: La lógica del despojo o por \\ qué el neoextractivismo es incompatible \\ con el derecho de propiedad comunitaria \\ de la tierra de los Pueblos Indígenas. \\ La importancia del rol del Estado ${ }^{1}$
}

Joaquín Gutiérrez ${ }^{2}$ | Universidad Nacional de la Plata

Revista Derechos en Acción ISSN 2525-1678/ e-ISSN 2525-1686

Año 4/NNo 11 Otoño 2019 (21 marzo a 21 junio), 543-603

DOl: https://doi.org/10.24215/25251678e290

ORCID: https://orcid.org/0000-0002-4574-5554

\section{Introducción}

En el contexto de acceso a la justicia y derechos humanos, se plantea en el presente trabajo abordar la temática de propiedad comunitaria de la tierra de los pueblos indígenas y su íntima relación con los derechos económicos, sociales y culturales. El desarrollo se estructurará sobre la base del concepto de (neo) extractivismo $^{3}$, acuñado por la socióloga argentina Maristella

\footnotetext{
1 Trabajo final presentado en el Curso de "Seminario sobre Derechos Humanos y Acceso a la Justicia. El desafío desde el derecho administrativo", Instituto de Derechos Humanos, Facultad de Ciencias Jurídicas y Sociales, UNLP, a cargo del Dr. Fabián Salvioli y el profesor Guillermo Rizzi.

2 Estudiante de la carrera de Abogacía en la Facultad de Ciencias Jurídicas y Sociales de la UNLP.

3 Maristella Svampa; Enrique Viale Trazar; “Continuidad y radicalización del neoextractivismo en Argentina"; Perfiles Económicos N³, Julio 2017, pp. 87-97, ISSN 0719-756X.
} 
Svampa ${ }^{4}$, cuyo desentrañamiento posicionará la discusión desde una perspectiva crítica y de visibilización de las distintas problemáticas que dicho modelo económico-productivo implica para las comunidades indígenas argentinas y americanas en general.

Siendo de especial preocupación la situación alarmante que los pueblos indígenas sufren en relación a la posesión, reivindicación y desalojo de sus tierras ancestrales de manera homogénea en el territorio, a nivel continental, en adición a las consecuentes violaciones a sus derechos humanos, es que se pretende por su relevancia socio-cultural abordar dicha temática.

El esquema de desarrollo del trabajo se enfocará en poner en relieve la problemática de la posesión de la tierra y de las violaciones de derechos humanos a las comunidades indígenas tanto en la Argentina como en América, deslizando una breve aproximación histórico-conceptual de dicha temática, así como de la lógica extractivista de desarrollo perseguida por los países. Se determinará el marco jurídico-normativo desde el cual se erigirá toda la construcción teórica, que junto con datos precisos sobre la situación de despojo y/o violaciones de derechos humanos que sufren distintas comunidades indígenas, conformará la base sustancial o punto de partida para el desarrollo del trabajo.

Ocupará un lugar central la exposición detallada de los derechos de los pueblos indígenas según la Comisión Interamericana de Derechos Humanos, sus alcances, las obligaciones estatales para con los mismos en relación al respeto de sus derechos (de manera genérica y en particular en el contexto de proyectos de desarrollo e inversión de actividades extractivas de recursos naturales), así como su recepción legislativa en argentina.

Todo ello tendrá como objetivo verificar la relación problemática que existe entre el derecho a la propiedad comunitaria de la tierra de los pueblos indígenas y sus recursos naturales, en

4 Investigadora del Conicet y Profesora de la Universidad Nacional de La Plata, Argentina 
contraposición a la lógica de la "visión eldoradista" que ostenta el discurso neoextractivista sobre los mismos. De igual manera, será objetivo principal de este trabajo explicar la relación de causa-efecto que implica el avance de la frontera agrícola (elemento esencial para comprender el neoextractivismo) sobre los desalojos forzados a las comunidades indígenas. Como corolario, será objeto de demostración, a modo de hipótesis, la incompatibilidad que existe entre el sistema de producción neoextractivista y el desarrollo y subsistencia de las culturas originarias, en tanto el citado modelo supone la utilización no sustentable de la tierra, colisionando así con la cosmovisión que estas culturas tienen sobre la misma. Ello pone en peligro la supervivencia de la cultura de los pueblos originarios, propiciando su asimilación con la cultura occidental, y constituyéndose en tanto violatorio de sus derechos humanos. En resumen, la propuesta será iluminar los cimientos de un modelo económico que se desarrolla a expensas de violaciones de derechos humanos dirigidas a los pueblos indígenas.

\section{Estado de situación}

Resulta cuanto menos ingenuo, por no decir negacionista, presentar la temática del despojo sufrido por los Pueblos Originarios de América como una mera cuestión de actualidad. Las múltiples atrocidades y sufrimientos que dichos pueblos han debido atravesar a lo largo de la historia, como consecuencia de la penetración cultural de occidente en su mundo, precisarían incontables páginas para ser cabalmente expresados. No atañe ello al desarrollo del presente trabajo, pero no por dicho motivo debe dejar de tenerse presente.

La historia de lucha y reconocimiento de derechos que es común a estos pueblos es una historia extensa y que ha conquistado,

5 Svampa, Maristella 2012 “Consenso de los commodities, giro ecoterritorial y pensamiento crítico en América Latina" en OSAL (Buenos Aires: CLACSO) Año XIII, N 32, noviembre. Pp 16. Disponible en: http://biblioteca.clacso.edu.ar/clacso/osal/20120927103642/0SAL32.pdf 
no mucho tiempo atrás, la reivindicación de su cosmovisión en independencia con la impuesta desde el mundo occidental.

Fue la Organización Internacional del Trabajo (OIT), quien se consagró como pionera en el estudio de la problemática y los derechos de los Pueblos Indígenas. Su labor, que comenzó en 1920, culminó en 1957 con la adopción del Convenio 107 sobre Poblaciones Indígenas y Tribales, referida a los derechos sobre la tierra, salud, condiciones de trabajo y educación, entre otros, y que constituyó el primer intento de codificación en la materia. Sin embargo, rápidamente fueron evidenciadas las falencias y defectos de dicho Convenio por los mismos pueblos indígenas, en tanto no consideraba la cosmovisión indígena como una alternativa de desarrollo, y por el contrario planteaba un "enfoque paternalista e integracionista: la integración a la sociedad nacional mayoritaria era el único futuro posible para dichos pueblos, al paso que todas las decisiones relacionadas con su desarrollo correspondían sólo al Estado y no a los propios pueblos que podían ser afectados por aquellas". ${ }^{6}$ A consecuencia de ello, en 1989, surge el Convenio 169 sobre Pueblos Indígenas y Tribales. El Convenio 169 plantea una dinámica distinta sobre el respeto a sus derechos, en tanto proporciona valor adicional a su identidad, sus tradiciones y sus formas de organización política, económica y social, dotándolos del derecho de participación en la toma de decisiones y la construcción política en general de los estados a los cuales pertenezcan. La Comisión Interamericana dice al respecto que dicho Convenio propuso "el respeto a la cultura e instituciones de los pueblos indígenas incluidas sus formas de gobierno y el derecho consuetudinario, con especial atención a las normas penales"7,

\footnotetext{
6 Gialdino, Rolando E.; “El rescate de la diferencia. Las comunidades indígenas en la jurisprudencia de la Corte Interamericana de Derechos Humanos"; Fuente: JA 2006 III 1178; Suplemento de Jurisprudencia Argentina; 6/9/2006.

7 Comisión Interamericana de Derechos Humanos; "La situación de los derechos humanos de los indígenas en las Américas"; 0EA/Ser.L/VII.108, Doc. 62, 20 octubre 2000, Original: Español. Disponible en: http://www.cidh.org/Indigenas/indice.htm
} 
de lo cual deducimos su relevancia. Dicho convenio fue ratificado por Argentina en 1984 y depositado ante la OIT en el año 2000, entrando en vigor en 2001.

Desde otra perspectiva, la Corte Interamericana ha tratado el tema de los Pueblos Indígenas en casos de jurisprudencia que han sido relevantes para la elucidación e interpretación de la Convención Americana de Derechos Humanos. La primer ocasión en que analizó la temática fue en el año 2001 con el "Caso de la Comunidad Mayagna (Sumo Awas Tingni) vs. Nicaragua". Las interpretaciones allí expuestas sobre la Convención fueron de valiosa utilidad como precedentes jurisprudenciales, en tanto denotaron una aproximación mayor al respeto por la cosmovisión de estos Pueblos; al igual que las que tuvieron lugar con posterioridad, como los casos "Comunidad Moiwana vs. Suriname" en 2005, "Comunidad Indígena Yakye Axa vs. Paraguay" y "Comunidad Indígena Sawhoyamaxa vs. Paraguay", entre otros.

En lo que atañe a las fuentes del derecho indígena en nuestro ordenamiento constitucional argentino, se podría bien decir que es de una completitud casi perfecta en la materia. Mediante la reforma constitucional del año 1994, nuestra Constitución Nacional ha adoptado con jerarquía constitucional en el artículo 75 inc. 22, entre otros tratados internacionales, a la Declaración Americana de los Derechos y Deberes del Hombre y a la Convención Americana de Derechos Humanos. La Corte Suprema de Justicia de la Nación, en correlato con la obligación que supone la ratificación de dichos instrumentos convencionales entiende que "la jurisprudencia de la Corte Interamericana debe servir de guía para la interpretación y aplicación de la Convención Americana por las autoridades nacionales." 8 Por lo que dicha jurisprudencia resultaría fuente del derecho constitucional. En adición, la reforma ha valido, a su vez, la incorporación de un artículo que precisamente reconoce los derechos de los Pueblos Originarios. Se trata del

8 Corte Sup., “Giroldi”, sent. del 7/4/1995, Fallos 318:514, entre otros, JA 1995 III 571. 
mismo artículo 75 inc. 17 sobre las atribuciones del Congreso de la Nación en materia de derecho indígena. ${ }^{?}$

En el ámbito interno del derecho argentino, no sólo se encuentra regulada la temática indígena, y sus derechos a la salud, alimentación, educación, respeto cultural y propiedad comunitaria de la tierra, entre otros, en la Constitución Nacional; de hecho existe una ley del Congreso de la Nación sobre ello, la Ley 23.303 sobre "Política Indígena y apoyo a las Comunidades Aborígenes. Objetivos. Comunidades Indígenas. Instituto Nacional de Asuntos Indígenas. Adjudicación de Tierras. Planes de Educación, Salud y Vivienda.", Sancionada y promulgada en el año 1985. Entre las cuestiones más relevantes que esta ley destaca, además de la consagración de extensos derechos para las Comunidades Indígenas, son la creación de un Instituto Nacional de Asuntos Indígenas como entidad descentralizada con participación indígena que fuera la institución responsable de velar por el cumplimiento de la citada ley, y por otro lado, prevé un procedimiento para la adjudicación de tierras y para el reconocimiento de su personería jurídica.

No obstante, a pesar de tan acabado sistema de fuentes del derecho indígena, no puede negarse su contradicción con la realidad respecto de su escasa efectividad. Como evidencia Rolando Gialdino, "la realidad cotidiana nos presenta los reiterados conflictos y tensiones que atraviesan a nuestro país, ante la habitual, secular y ominosa injusticia, cuando no invisibilidad, desdén e indiferencia, a la que están sometidas nuestras comunidades indígenas." ${ }^{10}$

9 Constitución de la Nación Argentina, artículo 75 inciso 17: "Reconocer la preexistencia étnica y cultural de los pueblos indígenas argentinos. Garantizar el respeto a su identidad y el derecho a una educación bilingüe e intercultural; reconocer la personería jurídica de sus comunidades, y la posesión y propiedad comunitarias de las tierras que tradicionalmente ocupan; y regular la entrega de otras aptas y suficientes para el desarrollo humano; ninguna de ellas será enajenable, transmisible, ni susceptible de gravámenes o embargos. Asegurar su participación en la gestión referida a sus recursos naturales y a los demás intereses que los afectan. Las provincias pueden ejercer concurrentemente estas atribuciones."

10 Gialdino, Rolando E.; "El rescate de la diferencia. Las comunidades indígenas en la jurisprudencia de la Corte Interamericana de Derechos Humanos"; Fuente: JA 2006 III 1178; Suplemento de Jurisprudencia Argentina; 6/9/2006. 
La razón por la que se propone abordar la temática de los derechos indígenas en contraposición con el modelo de neoextractivismo es que dichos pueblos ocupan en la actualidad territorios que son altamente codiciados por proyectos extractivos orientados a la exportación. El motivo es visibilizado con preocupación por la Comisión Interamericana de Derechos Humanos, quien expresa que "...con gran frecuencia, los proyectos de extracción, explotación y desarrollo coinciden con tierras y territorios históricamente ocupados por pueblos indígenas y tribales, y comunidades afrodescendientes. Ello se relaciona a que las tierras y territorios que tradicionalmente habitan estos pueblos suelen encontrarse en zonas que albergan una cantidad significativa de recursos naturales..."11

La existencia del paradigma del extractivismo existe, como modelo de producción y acumulación en América, con mayor o menor intensidad, desde la irrupción del pensamiento "civilizatorio" europeo y de su manipulación de los recursos. La riqueza latinoamericana fue el combustible de la revolución industrial porque propició la acumulación de capital y la distribución desigual mundial de la riqueza. Eduardo Galeano imprime al respecto: "El saqueo interno y externo, fue el medio más importante para la acumulación primitiva de capitales que, desde la Edad Media, hizo posible la aparición de una nueva etapa histórica en la evolución económica mundial (...) esta gigantesca masa de capitales creó un ambiente favorable a las inversiones en Europa, estimuló el "espíritu de empresa" y financió directamente el establecimiento de manufacturas que dieron un gran impulso a la revolución industrial". ${ }^{12}$ Ello importa un claro ejemplo del papel

\footnotetext{
11 Comisión Interamericana de Derechos Humanos; “Pueblos indígenas, comunidades afrodescendientes y recursos naturales: protección de derechos humanos en el contexto de actividades de extracción, explotación y desarrollo"; OEA/Ser.L/N/II. Doc. 47/1531 diciembre 2015; párr. 16; Disponible en: http://www.oas.org/es/cidh/informes/pdfs/IndustriasExtractivas2016.pdf

12 Galeano, Eduardo; "Las venas abiertas de América Latina"; Siglo Veintiuno Editores, Buenos Aires, 2012; Pp. 46-47.
} 
fundamental que han jugado históricamente los vastos recursos americanos en la construcción del paradigma capitalista y el rol que, en función de la división internacional del trabajo, ocupó Latinoamérica como proveedora de materias primas.

Si bien la mitad del siglo XX implicó en América Latina una incipiente industrialización sustitutiva de importaciones (en razón de una multifactorialidad, que no merece en el presente trabajo mayor detenimiento, pero que en alguna medida se debió al reconocimiento del "deterioro de los términos de intercambio entre el precio de los bienes primarios que se exportaron y los bienes industriales que se importaban"13), en las décadas subsiguientes dicho proceso se vio invertido. En el contexto de ajuste neoliberal y de dictaduras militares en la región (década del '70), se evidencia un retorno al tradicional paradigma como consecuencia del llamado Consenso de Washington. El lema esta vez propuesto retomaba la antigua concepción de matriz extractivista, en tanto se basó en la teoría de las ventajas comparativas, "utilizada para argumentar la necesidad de concentrarse en lo que el continente hacía mejor: producir commodities."

La problemática a la que en la actualidad asistimos, implica una acentuación de dicho modelo en tanto impera lo que para Svampa constituye un momento de cambio de época, en el cual se inserta el neoextractivismo. La autora lo define como una consecuencia del "Consenso de los Commodities", resultado de una alza en los precios internacionales de los productos primarios, que "tendieron a subrayar las ventajas comparativas del boom de los commodities"15, y que tuvo lugar en la década del 2000.

\footnotetext{
13 Lander, Edgardo; "El Neoextractivismo como modelo de desarrollo en América Latina y sus contradicciones"; Heinrich Böll Stiftung, Berlín, 13-14 de mayo de 2014; Disponible en: https://mx.boell.org/sites/default/files/edgardolander.pdf

14 Lander, Edgardo; "El Neoextractivismo como modelo de desarrollo en América Latina y sus contradicciones"; Heinrich Böll Stiftung, Berlín, 13-14 de mayo de 2014; Disponible en: https://mx.boell.org/sites/default/files/edgardolander.pdf

15 Maristella Svampa; Enrique Viale Trazar; "Continuidad y radicalización del neoextractivismo en Argentina"; Perfiles Económicos N³, Julio 2017, pp. 87-97, ISSN 0719-756X.
} 
Ahora bien, una vez delimitado el contexto histórico y definido el marco legal, creo que es de gran importancia realizar una aproximación a la problemática actual que este modelo supone y evidenciar así los perjuicios que irradia a las Comunidades originarias.

Si analizamos el resultado que la nueva política de neoextractivismo ha dejado en la Argentina observaremos datos atemorizantes. En nombre del avance de la frontera agropecuaria, por la implementación de cultivos transgénicos y de la ganadería intensiva, se deforestaron dos millones y medio de hectáreas en un período menor a diez años. El dato aportado por Darío Aranda en su libro "Tierra Arrasada" es el siguiente: "Si se computa el período 2004-2012, las topadoras arrasaron 2.501.912 de hectáreas, el equivalente a 124 veces la superficie de la Ciudad de Buenos Aires...", y agrega "en marzo de 2008, la Secretaría de Ambiente de la Nación reconoció el récord de desmonte en la Argentina y precisó que el ranking de deforestación estaba encabezado por Santiago del Estero (515.228) y Salta (414.934). Lejos, tercero, Chaco (127.491 hectáreas)." Por otro lado, Aranda agrega que "El gobierno nacional, junto a provincias y empresas, impulsa el Plan Estratégico Agroalimentario (PEA), que aspira a aumentar la producción granaria un 60 por ciento para 2020 (pasar de los 100 millones de toneladas actuales a 160 millones de toneladas). El mismo texto del PEA explicita un 27 por ciento de aumento del área sembrada (pasar de 32 millones de hectáreas a 41 millones). Se profundizará el avance sobre la zona del norte argentino."16

Monsanto, quien recibió la aprobación de una nueva semilla transgénica en el año 2012 por el Ministerio de Agricultura, controla el mercado de semillas no sólo en Argentina, sino en el mundo ( $86 \%$ del mercado de transgénicos le pertenece $\left.{ }^{17}\right)$.

\footnotetext{
16 Dario Aranda; "Tierra Arrasada. Petróleo, soja, pasteras y megaminería. Radiografía de la Argentina del Siglo XXI"; Sudamericana; Buenos Aires; 2015; P. 150-152

17 Dario Aranda; "Tierra Arrasada. Petróleo, soja, pasteras y megaminería. Radiografía de la Argentina del Siglo XXI"; Sudamericana; Buenos Aires; 2015; P. 18.
} 
Es la mayor corporación de agronegocios y una de las mayores productoras de agrotóxicos a nivel mundial.

Chevron, por su parte, quien recibió el otorgamiento de la concesión de una parte del territorio del yacimiento de hidrocarburos Vaca Muerta, fue condenada en Ecuador a una suma millonaria por contaminación ambiental (virtió alrededor de 100 millones de litros de crudo y contaminó territorios donde vivían pueblos indígenas campesinos). Sin embargo, se negó a pagar la condena y se encuentra prófuga de la Justicia ecuatoriana tras retirar sus activos del país. ${ }^{18}$

En este contexto, y solo por citar uno de los tantos ejemplos, la "Comunidad Iwi Imemb y" fue expulsada violentamente de su territorio ancestral en la provincia de Salta en el año 2003. Sus tierras fueron vendidas a la empresa transnacional Seaboard Corporation, la cual instaló mediante la empresa Tabacal Agroindustria, el asentamiento para la producción de azúcar más grande de Argentina (Ingenio San Martín El Tabacal). Tras el desalojo forzado la comunidad migró a la provincia de Buenos Aires. Hoy solicitan a dicha provincia, amparo de por medio, la adjudicación de tierras en la localidad de El Pato. ${ }^{19}$

En la estepa patagónica, la Comunidad mapuche Kaxipayiñ ocupa un territorio cuyo subsuelo alberga una de las mayores reservas de gas de la Argentina, el yacimiento Loma La Lata. Conviven con la explotación de hidrocarburos a pocos metros de sus casas, y como advierte Aranda, "La comunidad Kaxipayiñ enfrenta desde hace cuatro décadas un proceso de violación de derechos y son la prueba viviente de la contaminación. Metales pesados en sangre, abortos espontáneos, cáncer, diabetes y cegueras." ${ }^{20}$

\footnotetext{
18 Voz de América; "Ratifican millonaria condena a Chevron en Ecuador"; Quito, 11 de Julio de 2018. Disponible en: https://www.voanoticias.com/a/ratifican-millonaria-condenaa-chevron-en-ecuador-/4478384.html

19 Juzgado en lo Civil, Comercial y Contencioso Administrativo Federal de La Plata N4, Secretaría N011; “Comunidad Iwi Imemb y (Hijos de la Tierra) c/ Poder Ejecutivo Provincial Provincia de Buenos Aires y otros s/ amparo colectivo"; La Plata, 22 de mayo de 2018.

20 Darío Aranda; “Tierra Arrasada. Petróleo, soja, pasteras y megaminería. Radiografía de la Argentina del Siglo XXI"; Sudamericana; Buenos Aires; 2015; P. 31.
} 
En el año 2010 se contabilizaron en el noroeste argentino aproximadamente 5 millones de hectáreas de territorios en disputa por conflictos territoriales y ambientales, lo que equivaldría a la superficie de la provincia de Jujuy, y 600 mil personas afectadas en consecuencia de ello, que mayoritariamente fueron identificadas como campesinos e indígenas. ${ }^{21}$ En el año 2011, el entonces relator de la ONU sobre los pueblos indígenas, James Anaya, visitó la Argentina para recoger testimonios y denuncias de las comunidades. Su informe final "muestra un cuadro muy preocupante donde se subraya el impacto ambiental y cultural, la fragmentación del tejido social, la falta de consulta previa (Convenio 169 de la OIT), los desalojos violentos, las situaciones de criminalización y represión, entre otros". ${ }^{22}$

Las violaciones a los derechos humanos de las comunidades indígenas en Argentina se multiplican en tanto se implementa el acordado plan de reestructuración de la producción agrarioexportadora y de la megaminería y extracción de hidrocarburos. "Sólo en el NOA hay 150 activistas socioambientales judicializados. El observatorio de Derechos Humanos de Pueblos Indígenas (ODHPI) contabilizó 347 integrantes del Pueblo Mapuche judicializados en Neuquén por defender el territorio (...) En los últimos años se sucedieron asesinatos y muertes dudosas (catalogadas como accidentes por la policía pero denunciadas como asesinatos por las organizaciones sociales): Javier Chocobar (diaguita de Tucumán), Sandra Juárez (campesina de Santiago del Estero), Roberto López (qom de Formosa), Mario López (pilagá de Formosa), Mártires López (qom de Chaco), Cristian Ferreyra (Santiago del Estero), Miguel Galván (lule-vilela de Santiago del Estero), Celestina Jara y la beba de diez meses Lila Coyipé (ambas qom de La Primavera, Formosa),

21 Darío Aranda; "Los desplazados por la soja y la minería"; Página 12, Buenos Aires, 22 de febrero de 2010. Disponible en: https://www.pagina12.com.ar/diario/ elpais/1-140779-2010-02-22.html

22 Maristella Svampa; Enrique Viale Trazar; "Continuidad y radicalización del neoextractivismo en Argentina"; Perfiles Económicos N³, Julio 2017, pp. 87-97, ISSN 0719-756X. 
Imer Flores (qom de Chaco), Juan Daniel Díaz Asijak (qom de La Primavera), Florentín Díaz (qom de Chaco)."23

Los conflictos territoriales se integran a los ambientales. La deforestación y la contaminación por agrotóxicos y desechos industriales agrava la situación de desamparo de los pueblos originarios. Las consecuencias se evidencian en el cambio de la dinámica ambiental natural, por cuanto inundaciones, sequías, desertificación y pérdida de la biodiversidad son algunas de las que sufren de forma directa las Comunidades Indígenas y campesinas del norte del país.

La lucha de los Pueblos Indígenas es una lucha invisibilizada y repudiada por los sectores de poder y los medios de comunicación en complicidad con ellos. Dicha complicidad se evidencia fácilmente en sus discursos; la importancia en la transmisión de la información siempre será, tanto para los políticos como para los medios comunicadores, la de acentuar la gran posibilidad de "desarrollo" y "soberanía" que estos megaproyectos generan en el país. Difícilmente se observará una crítica razonada de los costos humanos y medioambientales de tales instalaciones productivas.

\section{Desarrollo}

En lo que atañe a la estructura del presente punto y para lograr una mejor profundidad conceptual, el mismo se dividirá en cuatro apartados. En el primero de ellos se abordará la temática del neoextractivismo, considerando los elementos esenciales para comprender dicho modelo y las consecuencias que genera sobre las distintas áreas productivas. En segundo lugar, detallaremos los derechos de los Pueblos Indígenas a sus territorios y recursos naturales según la Comisión Interamericana, así como también a los derechos de consulta y participación, comprendiendo la relación que los une con los

23 Dario Aranda; "Tierra Arrasada. Petróleo, soja, pasteras y megaminería. Radiografía de la Argentina del Siglo XXI"; Sudamericana; Buenos Aires; 2015; P. 19-20. 
derechos económicos, sociales y culturales. El punto siguiente versará sobre las obligaciones estatales frente a estos Pueblos Indígenas en relación al respeto de sus derechos (derecho de propiedad, salud, educación, respeto cultural, etc.) y en específico en los contextos de actividades extractivas llevadas a cabo en sus territorios. Como cuarto y último, se analizarán las violaciones a los derechos humanos que implican algunas formas de proyectos extractivos y los impactos que generan en las comunidades indígenas, analizando la íntima relación que guarda la protección de esos derechos con la garantía del goce de otros derechos humanos económicos, sociales y culturales.

\section{A. Neoextractivismo}

El neoextractivismo se enmarca dentro de un período de cambio de paradigma, que toma lugar en el lapso de tiempo correspondiente a los años 2000 a 2003. En razón de una suba internacional en los precios de los productos primarios, sucedió lo que pasó a denominarse "Boom de los Commodities". ${ }^{24}$ Ello trajo aparejado un consecuente cambio de época para la región, posicionando a los países latinoamericanos dentro de un contexto de rentabilidad extraordinaria que delineó "un patrón de acumulación basado en la sobre-explotación de bienes naturales, cada vez más escasos, en gran parte no renovables (...)"25, definición que utiliza Svampa para referir a dicho proceso.

Las características principales que lo definen incluyen fundamentalmente una "expansión de las fronteras de explotación de territorios antes considerados como improductivos" ${ }^{26}$, con la finalidad de poder hacer frente a la alta demanda internacional

\footnotetext{
24 Concepto de commodities en un sentido amplio, como productos indiferenciados cuyos precios se fijan internacionalmente y no requieren tecnología avanzada para su fabricación y procesamiento.

25 Maristella Svampa; Enrique Viale Trazar; "Continuidad y radicalización del neoextractivismo en Argentina"; Perfiles Económicos N³, Julio 2017, pp. 88, ISSN 0719-756X.

26 Maristella Svampa; Enrique Viale Trazar; "Continuidad y radicalización del neoextractivismo en Argentina"; Perfiles Económicos N³, Julio 2017, pp. 88, ISSN 0719-756X.
} 
de productos primarios, los que en razón de otra característica fundamental de este modelo, se encuentran orientados a la exportación a gran escala.

El neoextractivismo se caracteriza además por la inmensa magnitud de los emprendimientos, que en su parte mayoritaria resultan de inversiones extranjeras de corporaciones transnacionales y que se constituyen como inversiones de carácter "capital-intensivo y no trabajo intensivo"; por citar un ejemplo "para el caso de la minería a gran escala, por cada millón de dólares invertido, se crean apenas entre 0,5 y 2 empleos directos". ${ }^{27}$

La dinámica territorial que implica el modelo de producción neoextractivista supone una ocupación intensiva del territorio y el acaparamiento y concentración de la tierra. Las formas de producción se relacionan íntimamente con el monocultivo y la monoproducción y la fuerte presencia de la utilización de agroquímicos, en relación al tipo de actividad extractiva de que se trate.

Es posible notar que a lo largo del trabajo se ha vislumbrado el fenómeno conocido como "Consenso de los Commodities", cuya explicación conceptual deviene, en esta parte específica del trabajo, de utilidad para comprender con mayor profundidad la dinámica del neoextractivismo. "En el último decenio, América Latina realizó el pasaje del Consenso de Washington (...) al Consenso de los commodities" ${ }^{28}$, dicho cambio de paradigma supuso un giro de una etapa característica de la valorización financiera, en conjunto con políticas de ajuste y privatización, hacia una etapa orientada a los proyectos extractivos con finalidad de exportación vinculada al concepto de progreso y a una visión productivista del desarrollo. Este Consenso se materializó de

\footnotetext{
27 Maristella Svampa; "El Consenso de los Commodities. Extractivismo en América Latina"; Le Monde Diplomatique, edición Cono Sur; Edición de Junio de 2013/ N. ${ }^{0} 168$. Disponible en: https:// www.eldiplo.org/la-trampa-de-los-recursos-naturales/el-consenso-de-los-commodities/

28 Svampa, Maristella 2012 "Consenso de los commodities, giro ecoterritorial y pensamiento crítico en América Latina" en OSAL (Buenos Aires: CLACSO) Año XIII, № 32, noviembre. Pp 16. Disponible en: http://biblioteca.clacso.edu.ar/clacso/osal/20120927103642/0SAL32.pdf
} 
forma homogénea en los países latinoamericanos, independientemente del sesgo ideológico de cada gobierno, lo que denotó una gran flexibilidad en la disposición del rol del Estado, coexistiendo el mismo plan productivista en gobiernos de derecha como a su vez en gobiernos de izquierda. Como señala Edgardo Lander, luego de arrojar los resultados de las estadísticas sobre exportación de productos primarios desde el 2002 hasta el 2011 en América Latina, "nos encontramos con que no hay ninguna diferencia entre los países con gobiernos neoliberales como Colombia, Perú y Chile, o de los gobiernos que podrían calificarse de socialdemócratas como Argentina, Uruguay y Brasil, y los llamados gobiernos de izquierda o revolucionarios como Ecuador, Bolivia y Venezuela". Y agrega, "(n)os encontramos en presencia (...) de un nuevo fenómeno: el neoextractivismo progresista." 29

Ahora bien, si consideramos las consecuencias que ha traído la implementación de este modelo podemos observar, en primer lugar, que ha conducido a una "reprimarización de las economías" 30; lo que podría explicarse como una revalorización de la concepción extractivista y del rol de productores de materia prima, en el contexto de la división internacional (tradicional e histórica) del trabajo, cuyo valor agregado es escaso en relación a los bienes industrializados de importación. El peso económicopolítico que supone es "reformula(r) una vez más las históricas asimetrías entre el centro y la periferia" generando una "distribución desigual de los conflictos socioambientales" 31 en el mundo.

Las actividades extractivas, que abarcan desde la expansión de fronteras para la producción sojera, forestal y pesquera, la

29 Lander, Edgardo; "El Neoextractivismo como modelo de desarrollo en América Latina y sus contradicciones"; Heinrich Böll Stiftung, Berlín, 13-14 de mayo de 2014; Disponible en: https://mx.boell.org/sites/default/files/edgardolander.pdf

30 Maristella Svampa; Enrique Viale Trazar; "Continuidad y radicalización del neoextractivismo en Argentina"; Perfiles Económicos N³, Julio 2017, pp. 87-97, ISSN 0719-756X.

31 Maristella Svampa; Enrique Viale Trazar; "Continuidad y radicalización del neoextractivismo en Argentina"; Perfiles Económicos N³, Julio 2017, pp. 88, ISSN 0719-756X. 
instalación de la megaminería a cielo abierto, la explotación de hidrocarburos no convencional (por fractura hidráulica o fracking), hasta las megarrepresas y el acaparamiento de tierras, generan altos perjuicios socioambientales. Por un lado, su característica de orientación a la exportación de la producción (en el caso de la agricultura) atenta contra el concepto de soberanía alimentaria. Por otro, la extensión de la frontera de productividad implica deforestación, pérdida de biodiversidad y desalojos y expulsiones de poblaciones indígeno-campesinas. A todo ello se suma el impacto negativo en la salud causado por la contaminación por agroquímicos u otras sustancias utilizadas en procesos extractivos.

Desde el punto de vista social es posible advertir que genera una acentuación de la desposesión (despojo y concentración de tierras y recursos naturales) en tanto se constituye como una "dinámica vertical que irrumpe en los territorios, y a su paso va desestructurando economías regionales, destruyendo biodiversidad y profundizando de modo peligroso el proceso de acaparamiento de tierras, expulsando o desplazando comunidades rurales, campesinas o indígenas, y violentando procesos de decisión ciudadana." 32

Según Maristella Svampa, el neoextractivismo goza de una suerte de blindaje, en tanto expone que se encuentra protegido por un "discurso irrevocable", e insiste, "todos los gobiernos progresistas buscan justificar el extractivismo afirmando que es la vía que permite generar divisas, que luego son reorientadas a la redistribución del ingreso y al consumo interno, o bien hacia actividades con mayor contenido de valor agregado. Este discurso cuyo alcance real debería ser analizado caso por caso, busca oponer de modo reduccionista la cuestión social (la redistribución) con la cuestión ambiental, al tiempo que deja

\footnotetext{
32 Maristella Svampa; "El Consenso de los Commodities. Extractivismo en América Latina"; Le Monde Diplomatique, edición Cono Sur; Edición de Junio de 2013/ N. ${ }^{0} 168$. Disponible en: https://www.eldiplo.org/la-trampa-de-los-recursos-naturales/el-consenso-de-los-commodities/
} 
afuera discusiones complejas y fundamentales que enlazan de modo estratégico las problemáticas del desarrollo, el ambiente y la democracia." ${ }^{33}$ Así, se instaura en el discurso político la imposibilidad de visibilizar una alternativa u opción de desarrollo sustentable, implicando que "todo discurso crítico u oposición radical se inscrib(a) en el campo de la antimodernidad, de la negación del progreso, del "pachamamismo", del "ecologismo infantil" 34, y conllevando una negación de las consecuencias ambientales, sociales y culturales de los proyectos extractivos así como también una imposición sacrificial y productivista de la tierra.

Ello no imposibilitó que se suscitaran conflictos y resistencias por parte de grupos indígenas y ambientalistas. Sus cosmovisiones colisionan con la "visión productivista y eficientista del desarrollo, muy vinculada con la ideología del progreso y expansión de las fuerzas productivas" 35 y que suscribe la llamada mirada "eldoradista" acuñada por el sociólogo boliviano René Zavaleta (1986). Dicha visión se sustenta en un "mito fundante, de larga duración, ligado a la abundancia de los recursos naturales y sus ventajas (...) entendemos la visión eldoradista de los recursos naturales como una expresión regional de la actual ilusión desarrollista." 36

La expansión de las fronteras del capital, en tanto alineamiento con las directrices del neoextractivismo, implica un

33 Maristella Svampa; "El Consenso de los Commodities. Extractivismo en América Latina"; Le Monde Diplomatique, edición Cono Sur; Edición de Junio de 2013/ N. ${ }^{\circ} 168$. Disponible en: https://www.eldiplo.org/la-trampa-de-los-recursos-naturales/el-consenso-de-los-commodities/

34 Maristella Svampa; "El Consenso de los Commodities. Extractivismo en América Latina"; Le Monde Diplomatique, edición Cono Sur; Edición de Junio de 2013/ N. ${ }^{0} 168$. Disponible en: https://www.eldiplo.org/la-trampa-de-los-recursos-naturales/el-consenso-de-los-commodities/

35 Maristella Svampa; "El Consenso de los Commodities. Extractivismo en América Latina"; Le Monde Diplomatique, edición Cono Sur; Edición de Junio de 2013/ N. ${ }^{0} 168$. Disponible en: https://www.eldiplo.org/la-trampa-de-los-recursos-naturales/el-consenso-de-los-commodities/

36 Svampa, Maristella 2012 "Consenso de los commodities, giro ecoterritorial y pensamiento crítico en América Latina” en OSAL (Buenos Aires: CLACSO) Año XIII, №32, noviembre. Pp 26. Disponible en: http://biblioteca.clacso.edu.ar/clacso/osal/20120927103642/0SAL32.pdf 
proceso de "arrinconamiento de los pueblos originarios, colocados en la periferia de la periferia." ${ }^{37}$

\section{B. Derechos de los Pueblos Indígenas}

Debe notarse que durante el desarrollo de este apartado se abordarán los contenidos y alcances de los derechos indígenas según la Comisión Interamericana de Derechos Humanos (Organización de Estados Americanos - OEA). La elección de esta perspectiva de análisis tiene fundamento en que la misma aporta una visión totalizadora sobre la temática, basando su interpretación en conjugación con todas las fuentes internacionales del derecho indígena. A ello es menester agregar que durante los últimos años la Corte Interamericana de Derechos Humanos ha seguido esta misma línea interpretativa, teniendo como objetivo final el de crear un "corpus iuris coherente" 38 que unifique las disposiciones e interpretaciones de los instrumentos de la órbita de la OEA (Declaración Americana de los Derechos y Deberes del Hombre; Convención Americana sobre Derechos Humanos) con las de otros órganos y convenciones internacionales, entre los que se destacan el Convenio 169 de la Organización Internacional del Trabajo (OIT) y la Declaración de las Naciones Unidas sobre los Derechos de los Pueblos Indígenas. ${ }^{39}$

i. Fuentes del derecho y marco jurídico de los derechos territoriales

Si bien el sistema interamericano de derechos humanos no cuenta con ninguna normativa que expresamente refiera a

\footnotetext{
37 Maristella Svampa; Enrique Viale Trazar; "Continuidad y radicalización del neoextractivismo en Argentina"; Perfiles Económicos N³, Julio 2017, pp. 93, ISSN 0719-756X.

38 Comisión Interamericana de Derechos Humanos; "Derechos de los Pueblos Indígenas y Tribales sobre sus tierras ancestrales y recursos naturales. Normas y Jurisprudencia del Sistema Interamericano de Derechos Humanos"; OEA/Ser.L/V/II.; Doc. 56/09; 30 diciembre 2009. P. 8. Disponible en: http://www.oas.org/es/cidh/indigenas/docs/pdf/Tierras-Ancestrales.ESP.pdf

39 Declaración de Naciones Unidas sobre los Derechos de los Pueblos Indígenas, adoptada por la Asamblea General de Naciones Unidas por medio de la resolución A/61/295, 61 período de sesiones (13 de septiembre de 2007).
} 
los derechos territoriales que tienen los pueblos indígenas, la interpretación que ha hecho la Corte Interamericana de Derechos Humanos sobre algunos artículos de la Declaración y de la Convención ha permitido extender la protección que reviste el derecho de propiedad ordinario hacia nuevas formas de protección de dicho derecho.

La citada protección al derecho territorial de los pueblos indígenas se fundamenta en los artículos XXIII ${ }^{40}$ de la Declaración Americana de los Derechos y Deberes del Hombre y en el artículo $21^{41}$ de la Convención Americana sobre Derechos Humanos. Con respecto a la interpretación de estos artículos y a la luz del carácter evolutivo de interpretación de las normas y principios que rigen el derecho internacional de los derechos humanos, la Comisión Interamericana de Derechos Humanos (en adelante CIDH) y la Corte Interamericana de Derechos Humanos (en adelante la Corte) han resuelto que el contenido de estos artículos y su alcance "protege(n) los derechos que tienen tales pueblos y sus integrantes sobre su tierra y sus recursos naturales, esto es, sobre sus territorios" ${ }^{\prime 2}$, en tanto dichos preceptos "reflejan principios jurídicos internacionales generales que han evolucionado en el sistema interamericano y

\footnotetext{
40 Artículo XXIII: “Toda persona tiene derecho a la propiedad privada correspondiente a las necesidades esenciales de una vida decorosa, que contribuya a mantener la dignidad de la persona y del hogar." Declaración Americana de los Derechos y Deberes del Hombre; Aprobada en la Novena Conferencia Internacional Americana, Bogotá, Colombia, 1948.

41 Artículo 21: “Derecho a la propiedad privada. 1. Toda persona tiene derecho al uso y goce de sus bienes. La ley puede subordinar tal uso y goce al interés social. // 2. Ninguna persona puede ser privada de sus bienes, excepto mediante el pago de indemnización justa, por razones de utilidad pública o de interés social y en los casos y según las formas establecidas por la ley." Convención Americana sobre Derechos Humanos (Pacto San José de Costa Rica); suscripta en la Conferencia Especializada Interamericana sobre Derechos Humanos, San José, Costa Rica 7 al 22 de noviembre de 1969.

42 Comisión Interamericana de Derechos Humanos; "Derechos de los Pueblos Indígenas y Tribales sobre sus tierras ancestrales y recursos naturales. Normas y Jurisprudencia del Sistema Interamericano de Derechos Humanos"; OEA/Ser.L/V/II.; Doc. 56/09; 30 diciembre 2009. P. 9. Disponible en: http://www.oas.org/es/cidh/indigenas/docs/pdf/Tierras-Ancestrales.ESP.pdf
} 
son aplicables dentro y fuera del mismo, y en esta medida son debidamente considerados en la interpretación y aplicación de las disposiciones de la Declaración Americana de los Derechos y Deberes del Hombre en el contexto de los pueblos indígenas". ${ }^{43}$ La misma línea interpretativa jurisprudencial de la Corte puede observarse en casos como "Comunidad Indígena Yakye Axa vs. Paraguay" donde la misma expresó claramente que "considera útil y apropiado utilizar otros tratados internacionales distintos a la Convención Americana (...) para interpretar sus disposiciones de acuerdo a la evolución del sistema interamericano, habida consideración del desarrollo experimentado en esta materia en el Derecho Internacional de los Derechos Humanos" ${ }^{44}$

Por otro lado, tanto la Comisión como la Corte han plasmado en diversas ocasiones su decisión de incluir, asimismo, dentro de las fuentes del derecho de los pueblos indígenas (además de a los tratados internacionales no pertenecientes a la órbita de la OEA) a la costumbre internacional. Para la CIDH "existe una norma de derecho internacional consuetudinario mediante la cual se afirman los derechos de los pueblos indígenas sobre sus tierras tradicionales". ${ }^{45}$

\section{ii. Derecho de Propiedad indígena sobre los territorios}

Los pueblos indígenas tienen derecho a la posesión, uso, ocupación y habitación de los territorios que históricamente han habitado, así como también a la delimitación y demarcación de sus territorios ancestrales que deberá culminar con la titulación de los mismos, y la cual deberá ser correspondiente a

43 CIDH, Informe No. 75/02, Caso 11.140, Mary y Carrie Dann (Estados Unidos), 27 de diciembre de 2002, párr. 129

44 Corte IDH. Caso Comunidad Indígena Yakye Axa Vs. Paraguay. Fondo, Reparaciones y Costas. Sentencia de 17 de junio de 2005. Serie C No. 125, párr. 127

$45 \mathrm{CIDH}$, Alegatos ante la Corte Interamericana de Derechos Humanos en el caso de Awas Tingni v. Nicaragua. Referidos en: Corte IDH. Caso de la Comunidad Mayagna (Sumo) Awas Tingni Vs. Nicaragua. Fondo, Reparaciones y Costas. Sentencia de 31 de agosto de 2001. Serie C No. 79, párr. 140(d). 
una porción de tierra "[de] extensión y calidad suficiente para la satisfacción de sus formas de vida". ${ }^{46}$

Ahora bien, es necesario, a priori, dar con la definición precisa de lo que incluye el término "pueblos indígenas" para adentrarnos en el desarrollo de sus derechos territoriales. Si bien no existe una precisa definición sobre pueblos indígenas dentro del derecho internacional, quien más se acerca a su precisión es el Convenio 169 de la OIT. El mismo establece que es imprescindible para caracterizar a los pueblos a los cuales será aplicable el Convenio, la autodeterminación de los mismos o la conciencia que tengan de su identidad indígena. El artículo 1.1.(b) del Convenio 169 de la OIT dispone que dicho tratado se aplicará "a los pueblos en países independientes, considerados indígenas por el hecho de descender de poblaciones que habitaban en el país o en una región geográfica a la que pertenece el país en la época de la conquista o la colonización o del establecimiento de las actuales fronteras estatales y que, cualquiera que sea su situación jurídica, conservan todas sus propias instituciones sociales, económicas, culturales y políticas, o parte de ellas." ${ }^{\not 7}$

Por su parte, el sistema de Naciones Unidas determina como factores para conceptualizar a las poblaciones indígenas los siguientes: "(i) prioridad en el tiempo, con respecto a la ocupación y uso de un territorio específico; (ii) la perpetuación voluntaria de la especificidad cultural, que puede incluir los aspectos de

46 CIDH, Tercer Informe sobre la Situación de los Derechos Humanos en Paraguay. Doc. OEA/ Ser./L/VII.110, Doc. 52, 9 de marzo de 2001, Capítulo IX, párr. 50, Recomendación 1.

47 En la Guía de Aplicación del Convenio No. 169, la OlT explica que "Ios elementos que definen a un pueblo indígena son tanto objetivos como subjetivos; los elementos objetivos incluyen: (i) la continuidad histórica, v.g. se trata de sociedades que descienden de los grupos anteriores a la conquista o colonización; (ii) la conexión territorial, en el sentido de que sus antepasados habitaban el país o la región; y (iii) instituciones sociales, económicas, culturales y políticas distintivas y específicas, que son propias y se retienen en todo o en parte. El elemento subjetivo corresponde a la autoidentificación colectiva en tanto pueblo indígena." OIT, “Los Derechos de los Pueblos Indígenas y Tribales en la Práctica - Una Guía sobre el Convenio No. 169 de la OIT". Programa para promover el Convenio Núm. 169 de la OIT (PRO 169), Departamento de Normas Internacionales del Trabajo, 2009, pág. 9. 
lenguaje, organización social, religión y valores espirituales, modos de producción, formas e instituciones jurídicas; (iii) la autoidentificación, así como el reconocimiento por otros grupos, o por las autoridades estatales, en tanto una colectividad diferenciada; y (iv) una experiencia de subyugación, marginalización, desposesión, exclusión o discriminación, ya sea que estas condiciones persistan o no." 48 Cabe destacar que estos factores no son excluyentes, sino que sólo intentan dar una aproximación a las características, que pueden o no constituirse como tales, siempre que la Declaración de las Naciones Unidas sobre los Derechos de los Pueblos Indígenas ha optado por no dar una definición de los mismos. Dicha Declaración advierte en su artículo 33.1 que "los pueblos indígenas tienen derecho a determinar su propia identidad o pertenencia conforme a sus costumbres y tradiciones".

Una vez abordado el tema que hasta aquí fue expuesto sobre la delimitación conceptual de pueblos indígenas, se desarrollará el derecho sobre los territorios que ancestralmente ocupan.

Si bien el sistema interamericano no posee una norma expresa que consagre el derecho de propiedad de los pueblos indígenas sobre sus territorios, la Corte lee en los artículos XXIII ${ }^{49}$ de la Declaración y 21 de la Convención un amparo legal a dicho derecho de propiedad. ${ }^{50}$

48 ONU - Consejo Económico y Social - Comisión de Derechos Humanos - Subcomisión sobre la Prevención de la Discriminación y la Protección de las Minorías - Grupo de Trabajo sobre Poblaciones Indígenas: "Working Paper by the Chairperson-Rapporteur, Mrs. EricaIrene A. Daes, on the concept of 'indigenous people'". Documento ONU E/CN.4/Sub.2/ AC.4/1996/2, 10 de junio de 1996, párrs. 69-70.

$49 \mathrm{La} \mathrm{CIDH}$ ha expresado que el derecho de propiedad consagrado en el art. XXIII de la Declaración Americana "debe ser interpretado y aplicado en el contexto de las comunidades indígenas con la debida consideración por los principios que se relacionan con la protección de las formas tradicionales de propiedad y supervivencia cultural y de los derechos a la tierra, los territorios y los recursos"; CIDH, Informe No. 40/04, Caso 12.053, Comunidades Indígenas Mayas del Distrito de Toledo (Belice), 12 de octubre de 2004, párr. 115.

50 La Corte entiende que "tanto la propiedad privada de los particulares como la propiedad comunitaria de los miembros de las comunidades indígenas tienen la protección convencional 
El derecho de propiedad comunitaria de la tierra que ostentan los pueblos indígenas y sus miembros no sólo incluye la superficie terrestre sino que abarca la totalidad del territorio, los recursos naturales comprendidos en su superficie y en el subsuelo.

La CIDH sostiene un concepto amplio de tierra y territorios indígenas, donde el territorio es entendido como un todo inescindible. ${ }^{51}$ De esta forma quedan alcanzados tanto los espacios físicamente ocupados por las comunidades como también todos aquellos que estas utilicen para sus actividades culturales o de subsistencia, al igual que las vías de acceso a estos lugares, ya que "esta visión es acorde con la realidad cultural de los pueblos indígenas y su relación especial con la tierra y el territorio, así como los recursos naturales y el medio ambiente en general". ${ }^{2}$

La propiedad de la tierra de los pueblos indígenas tiene carácter comunitario, lo que la distingue del derecho tradicional de propiedad privada. La titularidad de dicho derecho es

que les otorga el artículo 21 de la Convención Americana": Corte IDH. Caso Comunidad Indígena Yakye Axa Vs. Paraguay. Fondo, Reparaciones y Costas. Sentencia de 17 de junio de 2005. Serie C No. 125, párr. 143.

51 La Corte Interamericana ha explicado en este sentido que "...el alcance del 'respeto' al derecho al territorio de los miembros [de un pueblo indígena o tribal] [no se limita] a, únicamente, sus 'aldeas, asentamientos y parcelas agrícolas'. Dicha limitación no tiene en cuenta la relación que los integrantes de los pueblos indígenas y tribales tienen con el territorio en su conjunto y no sólo con sus aldeas, asentamientos y parcelas agrícolas" [Corte IDH. Caso del Pueblo Saramaka Vs. Surinam. Excepciones Preliminares, Fondo, Reparaciones y Costas. Sentencia de 28 de noviembre de 2007. Serie C No. 172, párr. 114].

$52 \mathrm{CIDH}$, Informe de Seguimiento - Acceso a la Justicia e Inclusión Social: El camino hacia el fortalecimiento de la Democracia en Bolivia. Doc. OEA/Ser/L/V/II.135, Doc. 40, 7 de agosto de 2009, párr. 160. - En palabras de la Corte, "el territorio incluye un área física conformada por un núcleo de casas, recursos naturales, cultivos, plantaciones y su entorno, ligados en lo posible a su tradición cultural"; CIDH, Alegatos ante la Corte Interamericana de Derechos Humanos en el caso de Yakye Axa v. Paraguay. Referidos en: Corte IDH. Caso Comunidad Indígena Yakye Axa Vs. Paraguay. Fondo, Reparaciones y Costas. Sentencia de 17 de junio de 2005. Serie C No. 125, párr. 120(h). - “va más allá del establecimiento de aldeas específicas e incluye tierras que se utilizan para la agricultura, la caza, la pesca, la recolección, el transporte, la cultura y otros fines"; CIDH, Informe No. 40/04, Caso 12.053, Comunidades Indígenas Mayas del Distrito de Toledo (Belice), 12 de octubre de 2004, párr. 129. 
ostentada por el pueblo correspondiente como una comunidad. El derecho colectivo de propiedad implica que su ejercicio es llevado a cabo por la comunidad entera, es decir, por la comunidad como un todo. ${ }^{53}$

Si bien la Corte ha delimitado una diferenciación entre este tipo de propiedad comunitaria y el tipo tradicional de propiedad individual, otorga igual protección a ambas bajo el art. 21 de la Convención, en el "Caso Comunidad Indígena Sawhoyamaxa vs. Paraguay" la misma expuso que "desconocer las versiones específicas del derecho al uso y goce de los bienes, dadas por la cultura, usos, costumbres y creencias de cada pueblo, equivaldría a sostener que sólo existe una forma de usar y disponer de los bienes, lo que a su vez significaría hacer ilusoria la protección del artículo 21 de la Convención para millones de personas". ${ }^{54}$ Esta dimensión colectiva que el derecho de propiedad indígena

53 La Corte Interamericana ha notado que "entre los indígenas existe una tradición comunitaria sobre una forma comunal de la propiedad colectiva de la tierra, en el sentido de que la pertenencia de ésta no se centra en un individuo sino en el grupo y su comunidad"; Corte IDH. Caso de la Comunidad Mayagna (Sumo) Awas Tingni Vs. Nicaragua. Fondo, Reparaciones y Costas. Sentencia de 31 de agosto de 2001. Serie C No. 79, párr. 149. - Por su parte, la $\mathrm{CIDH}$ ha explicado que los derechos y libertades indígenas frecuentemente se ejercen y gozan en forma colectiva, en el sentido de que sólo pueden ser debidamente asegurados a través de su garantía a una comunidad indígena como un todo; CIDH, Informe No. 40/04, Caso 12.053, Comunidades Indígenas Mayas del Distrito de Toledo (Belice), 12 de octubre de 2004, párr. 113. CIDH, Informe No. 75/02, Caso 11.140, Mary y Carrie Dann (Estados Unidos), 27 de diciembre de 2002, párr. 128. CIDH, Resolución No. 12/85, Caso 7615, Pueblo Yanomami (Brasil), 5 de marzo de 1985. La CIDH ha subrayado que "al interpretar la Declaración Americana [de los Derechos y Deberes del Hombre] en el sentido de que salvaguarda la integridad, supervivencia y cultura de los pueblos indígenas mediante una protección efectiva de sus derechos humanos individuales y colectivos, la Comisión está respetando los propósitos mismos en que se funda la Declaración que, como lo expresa su Preámbulo, incluyen el reconocimiento de que 'es deber del hombre ejercer, mantener y estimular por todos los medios a su alcance la cultura, porque la cultura es la máxima expresión social e histórica del espíritu'". [CIDH, Informe No. 75/02, Caso 11.140, Mary y Carrie Dann (Estados Unidos), 27 de diciembre de 2002, párr. 131].

54 Corte IDH. Caso Comunidad Indígena Sawhoyamaxa Vs. Paraguay. Fondo, Reparaciones y Costas. Sentencia de 29 de marzo de 2006. Serie C No. 146, párr. 120. Corte IDH. Caso de la Comunidad Indígena Xákmok Kásek vs. Paraguay. Fondo, Reparaciones y Costas. Sentencia de 24 de agosto de 2010, Serie C No. 214, párr. 87. 
de la tierra conlleva implica un elemento fundamental para la realización efectiva de los derechos humanos de los pueblos indígenas en términos más generales. ${ }^{55}$

En lo que atañe al reconocimiento y propiedad de la tierra de las comunidades, es jurisprudencia de la Corte que no tiene implicancia alguna el reconocimiento oficial del Estado, puesto que el requisito para dicho reconocimiento, aunque no excluyente, está dado por el uso y posesión tradicionales de las tierras y recursos que realizaron los pueblos indígenas sobre sus territorios; a su respecto aclara la Corte que los territorios de los pueblos indígenas y tribales "les pertenecen por su uso u ocupación ancestral" 56 , y que"[c]omo producto de la costumbre, la posesión de la tierra debería bastar para que las comunidades indígenas que carezcan de un título real sobre la propiedad de la tierra obtengan el reconocimiento oficial de dicha propiedad y el consiguiente registro". ${ }^{57}$ Sin embargo, la posesión no es requisito formal para que se constituya el derecho de propiedad de la tierra, puesto que en los casos en los cuales las comunidades hayan perdido la posesión de los territorios que hubieren ocupado ancestralmente, estas mantienen sus derechos de propiedad, y son consecuentemente titulares del derecho a recuperarlas. ${ }^{58}$

Cuando el Estado otorga titulaciones o delimita territorios para su afectación a regímenes de propiedad comunitaria no

\footnotetext{
55 “[La] conexión particular entre las comunidades de pueblos indígenas y las tierras y recursos que han ocupado y usado tradicionalmente, cuya preservación es fundamental para la realización efectiva de los derechos humanos de los pueblos indígenas"; CIDH, Informe No. 75/02, Caso 11.140, Mary y Carrie Dann (Estados Unidos), 27 de diciembre de 2002, párr. 128. $56 \mathrm{CIDH}$, Acceso a la Justicia e Inclusión Social: El camino hacia el fortalecimiento de la Democracia en Bolivia. Doc. OEA/Ser.L/N/II, Doc. 34, 28 de junio de 2007, párr. 231.

57 Corte IDH. Caso de la Comunidad Mayagna (Sumo) Awas Tingni Vs. Nicaragua. Fondo, Reparaciones y Costas. Sentencia de 31 de agosto de 2001. Serie C No. 79, párr. 151. Corte IDH. Caso Comunidad Indígena Sawhoyamaxa Vs. Paraguay. Fondo, Reparaciones y Costas. Sentencia de 29 de marzo de 2006. Serie C No. 146, párr. 127.

58 Corte IDH. Caso Comunidad Indígena Sawhoyamaxa Vs. Paraguay. Fondo, Reparaciones y Costas. Sentencia de 29 de marzo de 2006. Serie C No. 146, párr. 128.
} 
otorga un derecho nuevo ${ }^{59}$, únicamente reconoce uno ya existente, y cuya existencia está dada por su uso consuetudinario. ${ }^{60}$

Otra cuestión que la $\mathrm{CIDH}$ ha aclarado respecto al derecho de propiedad de la tierra es que si bien la tenencia debe estar ligada a una continuidad histórica esta no debe ser necesariamente circunscripta a un solo lugar, ni a una ubicación específica de los asentamientos, puesto que a lo largo de los siglos fueron factibles movilizaciones de las poblaciones indígenas, y por ello "[la] ubicación específica de los asentamientos dentro del territorio ancestral no es determinante de la existencia de los derechos; puede haber movimientos en los lugares de asentamiento a lo largo de la historia, sin que se afecte la protección por la Convención Americana a los derechos de propiedad". ${ }^{61}$

59 La existencia del derecho aún sin el reconocimiento estatal o la posesión de título formal alguno, implica que las acciones de reconocimiento oficial "deben ser consideradas no como meras transferencias sino como procesos de otorgamiento de prueba para que las comunidades pudiesen acreditar su dominio anterior, y no como el otorgamiento de nuevos derechos"; CIDH, Tercer Informe sobre la Situación de los Derechos Humanos en Colombia. Doc. OEA/Ser.L/V/II.102, Doc. 9 rev. 1, 26 de febrero de 1999, Capítulo X, párr. 19.

60 El ejercicio de los derechos territoriales de los pueblos indígenas y tribales no está condicionado a su reconocimiento expreso por el Estado, y la existencia de un título formal de propiedad no es requisito para la existencia del derecho a la propiedad territorial indígena bajo el artículo 21 de la Convención [Corte IDH. Caso Comunidad Indígena Sawhoyamaxa Vs. Paraguay. Fondo, Reparaciones y Costas. Sentencia de 29 de marzo de 2006. Serie C No. 146, párr. 128]. La disociación entre el derecho consuetudinario de propiedad indígena y la existencia o no de un título formal de propiedad implica que el acto de titulación por parte de los Estados es un acto de reconocimiento y protección oficiales, que no es constitutivo, de derechos. Consecuentemente, la posesión y uso consuetudinario de los pueblos indígenas debe ser el criterio rector en la identificación y garantía de estos derechos a través de la titulación.

61 Así, la CIDH alegó ante la Corte Interamericana en el caso de Awas Tingni v. Nicaragua que los movimientos históricos de los asentamientos dentro del territorio ancestral no afectaban la existencia o titularidad de los derechos territoriales de la comunidad: "la mayoría de los pobladores de Awas Tingni llegaron en la década de 1940 al lugar en donde actualmente tienen su asentamiento principal, provenientes de su lugar ancestral antiguo: Tuburús. Se dio un movimiento de un lugar a otro dentro de su territorio ancestral; los ancestros Mayagnas estuvieron ahí desde tiempos inmemoriales" [CIDH, Alegatos ante la Corte Interamericana de Derechos Humanos en el caso de Awas Tingni v. Nicaragua. Referidos en: Corte IDH. Caso 
iii. Derecho de los pueblos indígenas sobre los recursos naturales y la utilización del territorio

El derecho territorial de los pueblos indígenas incluye el reconocimiento del derecho de controlar, usar y gozar de sus territorios y los recursos naturales que en ellos se encuentren, con las modalidades o formas "dadas por la cultura, usos, costumbres y creencias de cada pueblo". ${ }^{62}$ Así, su relación tradicional con el territorio "puede expresarse de distintas maneras, según el pueblo indígena del que se trate y las circunstancias concretas en que se encuentre, y puede incluir el uso o presencia tradicional, ya sea a través de lazos espirituales o ceremoniales; asentamientos o cultivos esporádicos; caza, pesca o recolección estacional o nómada; uso de recursos naturales ligados a sus costumbres; y cualquier otro elemento característico de su cultura" ${ }^{63}$ Estos modos de uso del territorio están protegidos por el derecho a la propiedad. ${ }^{64}$

Los sistemas tradicionales de control y uso del territorio "son esenciales en muchas circunstancias para el bienestar individual y colectivo y en efecto para la supervivencia de los pueblos indígenas", toda vez que el control sobre la tierra se refiere "a su capacidad de brindarle recursos para el sustento" al pueblo correspondiente, así como "al espacio geográfico necesario para la reproducción cultural y social del grupo". 65

de la Comunidad Mayagna (Sumo) Awas Tingni Vs. Nicaragua. Fondo, Reparaciones y Costas. Sentencia de 31 de agosto de 2001. Serie C No. 79, párr. 140(h)].

62 Corte IDH. Caso Comunidad Indígena Sawhoyamaxa Vs. Paraguay. Fondo, Reparaciones y Costas. Sentencia de 29 de marzo de 2006. Serie C No. 146, párr. 120.

63 Corte IDH. Caso Comunidad Indígena Sawhoyamaxa Vs. Paraguay. Fondo, Reparaciones y Costas. Sentencia de 29 de marzo de 2006. Serie C No. 146, párr. 131.

64 No existe sólo una forma de usar y disfrutar de los bienes protegida por la Declaración Americana o la Convención Americana; tanto la propiedad como la posesión de los territorios por los pueblos indígenas y tribales pueden diferir de la concepción clásica de dominio, y en tal sentido son protegidas por el derecho a la propiedad. [Corte IDH. Caso Comunidad Indígena Sawhoyamaxa Vs. Paraguay. Fondo, Reparaciones y Costas. Sentencia de 29 de marzo de 2006. Serie C No. 146, párr. 120]

65 CIDH, Informe No. 75/02, Caso 11.140, Mary y Carrie Dann (Estados Unidos), 27 de diciembre de 2002, párr. 128. 
Como ya se ha mencionado, el sistema interamericano conjuga reglas de todo el espectro del derecho internacional, y haciendo eco de ello, ha respaldado parte de su jurisprudencia en materia de utilización del territorio y recursos naturales en normativa del Convenio 169 de la OIT $^{66}$, o a su vez, del Pacto Internacional de Derechos Civiles y Políticos, que en su artículo 27 establece el derecho de las personas pertenecientes a las minorías étnicas, religiosas o lingüísticas a disfrutar de su propia cultura, en conformidad con otros miembros del grupo. ${ }^{67}$

También ha establecido la CIDH que el derecho de los pueblos indígenas y tribales a la posesión de las tierras ancestrales se vincula directamente con el derecho de las personas indígenas a la identidad cultural, en la medida en que la cultura es una forma de vida intrínsecamente vinculada al territorio propio. ${ }^{68}$

El uso y goce del territorio comprende el derecho de propiedad sobre los recursos naturales que se encuentran dentro

66 El Convenio 169 de la OIT establece que es deber estatal el de "salvaguardar el derecho de los pueblos [indígenas] a utilizar tierras que no estén exclusivamente ocupadas por ellos, pero a las que hayan tenido tradicionalmente acceso para sus actividades tradicionales y de subsistencia", prestando particular atención a los casos de los pueblos nómadas y los agricultores itinerantes". Convenio 169, artículo 14.1.

67 CIDH, Informe No. 75/02, Caso 11.140, Mary y Carrie Dann (Estados Unidos), 27 de diciembre de 2002, párr. 130, nota al pie No. 97. El Comité de Derechos Humanos de la ONU ha explicado que "la cultura se manifiesta de muchas formas, inclusive un modo particular de vida relacionado con el uso de recursos terrestres, especialmente en el caso de los pueblos indígenas" [Comité de Derechos Humanos, Observación General No. 23: Los derechos de las minorías (Artículo 27 del PIDCP), 08/04/94, Doc. ONU CCPR/C/21/Rev. 1/Add.5, párrafo 7; citado en CIDH, Informe No. 75/02, Caso 11.140, Mary y Carrie Dann (Estados Unidos), 27 de diciembre de 2002, párr. 130, nota al pie No. 97].

68 Los Estados están obligados a adoptar "medidas especiales para garantizar el reconocimiento del interés particular y colectivo que los pueblos indígenas tienen en la ocupación y el uso de sus tierras y recursos tradicionales y su derecho a no ser privados de ese interés excepto con un previo consentimiento plenamente informado, en condiciones de [igualdad] y previa una justa compensación" CIDH, Informe No. 75/02, Caso 11.140, Mary y Carrie Dann (Estados Unidos), 27 de diciembre de 2002, párr. 131. "El derecho a la cultura incluye formas y modalidades distintivas de usar los territorios tales como las actividades tradicionales de pesca, caza y recolección en tanto elementos esenciales de la cultura indígena". Corte IDH. Caso Comunidad Indígena Yakye Axa Vs. Paraguay. Fondo, Reparaciones y Costas. Sentencia de 17 de junio de 2005. Serie C No. 125, párr. 140. 
y sobre los territorios, es decir, aquellos que tradicionalmente utilizan para su subsistencia y desarrollo, pero que también incluye tanto los usos de carácter cultural y espiritual o ceremonial. Para la Corte Interamericana, "el derecho a utilizar y gozar de las tierras que los miembros del pueblo (...) poseen tradicionalmente implica, necesariamente, gozar de un derecho similar respecto de los recursos naturales que son necesarios para su supervivencia". ${ }^{69}$

Cuando se hace referencia a la importancia que la propiedad sobre los recursos naturales implica para la supervivencia de los pueblos indígenas, no sólo se está haciendo referencia directa a las actividades económico-productivas mediante las cuales estas comunidades se desarrollan (caza, pesca, agricultura, etc.), sino que también compromete la continuación de la vida de los pueblos como tales, es decir, su idiosincrasia. "[L]a cultura de los miembros de las comunidades indígenas corresponde a una forma de vida particular de ser, ver y actuar en el mundo, constituido a partir de su estrecha relación con sus territorios tradicionales y los recursos que allí se encuentran, no sólo por ser éstos su principal medio de subsistencia, sino además porque constituyen un elemento integrante de su cosmovisión, religiosidad y, por ende, de su identidad cultural". ${ }^{70}$

En palabras de la Corte, "los integrantes de los pueblos indígenas y tribales tienen el derecho de ser titulares de los recursos naturales que han usado tradicionalmente dentro de su territorio por las mismas razones por las cuales tienen el derecho de ser titulares de la tierra que han usado y ocupado tradicionalmente durante siglos. Sin ellos, la supervivencia económica, social y cultural de dichos pueblos está en riesgo". ${ }^{71}$ Por ello la Corte

${ }^{69}$ Corte IDH. Caso del Pueblo Saramaka Vs. Surinam. Excepciones Preliminares, Fondo, Reparaciones y Costas. Sentencia de 28 de noviembre de 2007. Serie C No. 172, párr. 118-141. 70 Corte IDH. Caso Comunidad Indígena Yakye Axa Vs. Paraguay. Fondo, Reparaciones y Costas. Sentencia de 17 de junio de 2005. Serie C No. 125, párr. 135.

${ }^{71}$ Corte IDH. Caso Comunidad Indígena Yakye Axa Vs. Paraguay. Fondo, Reparaciones y Costas. Sentencia de 17 de junio de 2005. Serie C No. 125, párr. 137. Corte IDH. Caso 
destaca la importancia que reviste la protección de los derechos de los pueblos indígenas sobre los recursos naturales, aseverando que "el objetivo y el fin de las medidas requeridas en nombre de los miembros de los pueblos indígenas y tribales es garantizar que podrán continuar viviendo su modo de vida tradicional y que su identidad cultural, estructura social, sistema económico, costumbres, creencias y tradiciones distintivas serán respetadas, garantizadas y protegidas por los Estados". ${ }^{72}$

\section{iv. Derecho de consulta y participación}

Como correlato de los derechos de propiedad territorial, existe en cabeza de las comunidades indígenas otro derecho que se relaciona íntimamente con aquel; es el derecho a ser consultados y a participar sobre las decisiones que tomen terceros (el Estado y/o particulares, mayoritariamente empresas) sobre sus territorios ancestrales, o las que indirectamente se relacionen con sus territorios o sus modalidades de vida en general. Este derecho tiene, como es de esperarse, una fuerte carga de obligación para con los Estados y/o particulares, que deben satisfacer este requisito legal a la hora de realizar cualquier actividad, sea productiva o no, que involucre a los pueblos indígenas y/o sus territorios.

La CIDH imprime al respecto, "[l]os Estados tienen la obligación de consultar a los pueblos indígenas y garantizar su participación en las decisiones relativas a cualquier medida que afecte sus territorios" 73 , siendo de especial importancia y consideración la relación entre los pueblos indígenas y tribales y la tierra y los recursos naturales. ${ }^{74}$

Comunidad Indígena Sawhoyamaxa Vs. Paraguay. Fondo, Reparaciones y Costas. Sentencia de 29 de marzo de 2006. Serie C No. 146, párr. 118.

72 Corte IDH. Caso del Pueblo Saramaka Vs. Surinam. Excepciones Preliminares, Fondo, Reparaciones y Costas. Sentencia de 28 de noviembre de 2007. Serie C No. 172, párrs. 120, 121.

$73 \mathrm{CIDH}$, Democracia y Derechos Humanos en Venezuela. Doc. OEA/Ser.L/V/II, Doc. 54, 30 de diciembre de 2009, párr. 1058.

$74 \mathrm{CIDH}$, Democracia y Derechos Humanos en Venezuela. Doc. OEA/Ser.L/N/II, Doc. 54, 30 de diciembre de 2009, párr. 1071. 
La consulta debe perseguir la finalidad de obtener el consentimiento de los pueblos indígenas, pero con la particularidad de que éste, obligatoriamente, debe ser libre e informado ${ }^{75}$, según lo dispone la CIDH y en consonancia con lo que dispone el Convenio 169 de la OIT $^{76}$ y la Declaración de las Naciones Unidas sobre los Derechos de los Pueblos Indígenas. ${ }^{77}$

La mencionada consulta y el consentimiento incluyen, como se ha advertido, todo tipo de actividad, sea esta de carácter extractivo o no, que afecte los derechos de propiedad indígenas, así como también toda actividad administrativa o legislativa que realicen los Estados y que genere un impacto directo o indirecto sobre los derechos o intereses de los pueblos indígenas. ${ }^{78}$ Como el respeto de la cosmovisión indígena es de suma importancia

$75 \mathrm{CIDH}$, Informe de Seguimiento - Acceso a la Justicia e Inclusión Social: El camino hacia el fortalecimiento de la Democracia en Bolivia. Doc. OEA/Ser/L/V/II.135, Doc. 40, 7 de agosto de 2009, párr. 158.

76 El Convenio No. 169 de la OIT obliga a los Estados a consultar con los pueblos indígenas, de buena fe y con el objetivo de llegar a un acuerdo u obtener su consentimiento, sobre asuntos que les afectan en distintos contextos; ver los arts. 6.1, 6.2, 15.2, 22.3, 27.3 y 28 del Convenio.

77 Ver, entre otros, los artículos 10, 11, 15, 17, 19, 28, 29, 30, 32, 36 y 38 de la Declaración de la ONU.

78 El Relator Especial de las Naciones Unidas ha formulado la obligación general en los términos siguientes: "De conformidad con la Declaración de las Naciones Unidas sobre los derechos de los pueblos indígenas y con el Convenio No. 169 de la OIT, Ios Estados tienen el deber de consultar a los pueblos interesados, mediante procedimientos especiales y diferenciados sobre los asuntos que les conciernen, con la finalidad de obtener su consentimiento libre, previo e informado. Basado en el entendimiento de la marginación relativa y las condiciones desfavorables de los pueblos indígenas en relación con los procesos democráticos normales, este deber dimana del derecho primordial de los pueblos indígenas a la libre determinación y de los principios de soberanía popular y de gobierno por consentimiento y es un corolario de los principios conexos de derechos humanos. // El deber de celebrar consultas se aplica siempre que una decisión legislativa o administrativa pueda afectar a los pueblos indígenas en modos no percibidos por la población general del Estado, y en tales casos el deber se aplica en relación con los pueblos indígenas que se ven particularmente afectados y respecto de esos intereses particulares. El deber de celebrar consultas no solo se aplica cuando la medida propuesta se refiere a derechos sustantivos ya reconocidos en el derecho interno, como los derechos relativos a las tierras". ONU - Consejo de Derechos Humanos - Informe del Relator Especial sobre la situación de los derechos humanos y las 
para la CIDH y la Corte, en correlato con el artículo $23^{79}$ de la Convención Americana (que garantiza los derechos políticos y la participación ciudadana en la toma de decisiones políticas), la Corte ha interpretado que "el derecho a la participación política incluye el derecho a "participar en la toma de decisiones sobre asuntos y políticas que inciden o pueden incidir en sus derechos...desde sus propias instituciones y de acuerdo a sus valores, usos, costumbres y formas de organización". ${ }^{80}$

El derecho de los pueblos indígenas a ser consultados sobre las decisiones que puedan afectarlos se relaciona directamente con el derecho a la identidad cultural, en la medida en que la cultura puede resultar afectada por tales decisiones. ${ }^{81}$ Es por ello que todas aquellas decisiones administrativas que tengan como consecuencia una alteración jurídica o de cualquier índole en los derechos o intereses de las comunidades indígenas sobre sus territorios deben basarse en un proceso de participación plena, como salvaguarda de dicha cultura que quiere preservarse. ${ }^{82}$

libertades fundamentales de los indígenas, James Anaya. Doc. ONU A/HRC/12/34, 15 de julio de 2009, párrs. 62-63.

79 “Artículo 23: Derechos Políticos / 1. Todos los ciudadanos deben gozar de los siguientes derechos y oportunidades: a) de participar en la dirección de los asuntos públicos, directamente o por medio de representantes libremente elegidos; b) [...]" [Convención Americana sobre Derechos Humanos (Pacto San José de Costa Rica)"; suscripta en la Conferencia Especializada Interamericana sobre Derechos Humanos, San José, Costa Rica 7 al 22 de noviembre de 1969.]

80 Corte IDH, Caso Yatama Vs. Nicaragua. Sentencia de 23 de junio de 2005. Serie C No. 127, párr. 225.

$81 \mathrm{CIDH}$, Democracia y Derechos Humanos en Venezuela. Doc. OEA/Ser.L/N/II, Doc. 54, 30 de diciembre de 2009, párr. 1050.

82 Es doctrina de la CIDH que "Ios artículos XVIII y XXIII de la Declaración Americana obligan especialmente a los Estados miembros a garantizar que toda determinación de la medida en que los reclamantes indígenas mantienen intereses en las tierras de las que han poseído tradicionalmente título y que han ocupado y utilizado, se base en un proceso de total información y mutuo consentimiento de parte de la comunidad indígena en su conjunto; esto requiere, como mínimo, que todos los miembros de la comunidad estén plena y cabalmente informados de la naturaleza y las consecuencias del proceso y se les brinde una oportunidad efectiva de participar individual o colectivamente". CIDH, Informe No. 75/02, Caso 11.140, Mary y Carrie Dann (Estados Unidos), 27 de diciembre de 2002, párr. 140. 
Ahora bien, estos procesos de consulta, consentimiento y participación revisten una importancia esencial en el contexto de proyectos o concesiones de implementación extractiva de recursos naturales o del suelo en los territorios de propiedad indígena; en tanto aquellos proyectos son susceptibles de generar consecuencias en y sobre sus formas de vida. De allí que para la aprobación de planes o proyectos de inversión o desarrollo de los recursos naturales sea requisito anterior el consentimiento libre e informado de los pueblos indígenas que habiten el territorio, quienes participarán en el proceso de consulta a través de sus propias instituciones y formas de organización. Y cuando se hace referencia a las formas propias de organización, se refiere a que la consulta, como proceso de diálogo y negociación, no reviste el carácter de singular, sino que involucra a la comunidad en su totalidad, en tanto afecta a los miembros individuales de dichos pueblos.

Por otro lado, el proceso de consulta debe basarse en la buena fe de las partes, y por ende "propender por la obtención del consentimiento libre e informado de los pueblos y no limitarse únicamente a una notificación o a un trámite de cuantificación de daños". ${ }^{83}$

En cuanto al momento en que debe comenzar la consulta, negociación y participación conjunta en los proyectos y concesiones de explotación o extracción de los recursos naturales, esta debe realizarse desde que se realiza la evaluación misma del otorgamiento de la concesión: los Estados deben garantizar, de antemano, la participación efectiva del pueblo indígena o tribal afectado (con la finalidad de obtener el consentimiento libre, informado y previo de éstos, según sus costumbres y tradiciones), a través de sus métodos tradicionales de toma de decisiones, tanto en relación con el proceso de evaluación

$83 \mathrm{CIDH}$, Acceso a la Justicia e Inclusión Social: El camino hacia el fortalecimiento de la Democracia en Bolivia. Doc. OEA/Ser.L/N/II, Doc. 34, 28 de junio de 2007, párr. 248. 
del otorgamiento de concesiones en su territorio, como en la adopción de las decisiones correspondientes. ${ }^{84}$

v. Derechos territoriales como eje principal para el goce de otros derechos humanos

La satisfacción del derecho de propiedad de los pueblos indígenas sobre los territorios ancestrales implica un derecho de esencial importancia para el goce de otros derechos humanos. Podría decirse que sin su satisfacción no sería posible satisfacer otros derechos que se encuentran íntimamente relacionados con este, en razón de la idiosincrasia de los pueblos indígenas y de su especial relación con la tierra. De hecho, la posesión y el efectivo uso y goce del territorio tradicionalmente ocupado por las comunidades, implica la posibilidad de desenvolverse como cultura, de satisfacer sus necesidades de consumo y en general de realizar las diversas actividades que forman parte de su forma de vida.

Este apartado implica un punto de cohesión importante en el desarrollo del trabajo, puesto que aquí puede observarse como el derecho de propiedad comunitaria se relaciona directamente con los derechos económicos, sociales y culturales de los pueblos indígenas, y su coexistencia e interrelación.

A su respecto, observaremos como la Corte y la $\mathrm{CIDH}$ han puesto de manifiesto la interconexión existente entre el derecho de propiedad comunitaria de la tierra y los derechos a una vida digna, a la alimentación, a la salud, a la educación, a la cultura, los derechos laborales y los derechos económicos y sociales. Es doctrina de la CIDH que el impedimento al acceso a la tierra y los recursos naturales es causa directa del empobrecimiento de las comunidades e imposibilita el desarrollo de su cultura. ${ }^{85}$

84 Corte IDH. Caso del Pueblo Saramaka Vs. Surinam. Excepciones Preliminares, Fondo, Reparaciones y Costas. Sentencia de 28 de noviembre de 2007. Serie C No. 172, párr. 147.

85 “[L]a falta de titulación, delimitación, demarcación y posesión de los territorios ancestrales, al impedir o dificultar el acceso de los pueblos indígenas y tribales a la tierra y los 
Es doctrina de la Corte que "los Estados deben respetar la especial relación que los miembros de los pueblos indígenas y tribales tienen con su territorio a modo de garantizar su supervivencia social, cultural y económica". ${ }^{86}$ Para la CIDH, la relación especial entre los pueblos indígenas y tribales y sus territorios significa que "el uso y goce de la tierra y de sus recursos son componentes integrales de la supervivencia física y cultural de las comunidades indígenas y de la efectiva realización de sus derechos humanos en términos más generales". ${ }^{87}$ En esa misma línea, se arriba a concluir que dicha relación especial con el territorio es fundamental para la subsistencia del grupo y, por sobre todo, para su integridad cultural ${ }^{88}$, en tanto

recursos naturales, se vincula directamente y en tanto causa situaciones de pobreza y extrema pobreza entre familias, comunidades y pueblos", CIDH, Democracia y Derechos Humanos en Venezuela. Doc. OEA/Ser.L/V/II, Doc. 54, 30 de diciembre de 2009, párrs. 10761080. - Cuando los Estados no garantizan el derecho de propiedad territorial de las comunidades indígenas y sus miembros, ello implica una privación "no sólo de la posesión material de su territorio sino además de la base fundamental para desarrollar su cultura, su vida espiritual, su integridad y su supervivencia económica", CIDH, Alegatos ante la Corte Interamericana de Derechos Humanos en el caso de Yakye Axa v. Paraguay. Referidos en: Corte IDH. Caso Comunidad Indígena Yakye Axa Vs. Paraguay. Fondo, Reparaciones y Costas. Sentencia de 17 de junio de 2005. Serie C No. 125, párr. 120(j).

86 Corte IDH. Caso del Pueblo Saramaka Vs. Surinam. Excepciones Preliminares, Fondo, Reparaciones y Costas. Sentencia de 28 de noviembre de 2007. Serie C No. 172, párr. 91. La Corte Interamericana ha reiterado que "la estrecha relación que los indígenas mantienen con la tierra debe ser reconocida y comprendida como la base fundamental de sus culturas, su vida espiritual, su integridad y su supervivencia económica" [Corte IDH. Caso de la Comunidad Mayagna (Sumo) Awas Tingni Vs. Nicaragua. Fondo, Reparaciones y Costas. Sentencia de 31 de agosto de 2001. Serie C No. 79, párr. 149].

87 CIDH, Informe No. 40/04, Caso 12.053, Comunidades Indígenas Mayas del Distrito de Toledo (Belice), 12 de octubre de 2004, párr. 116. Corte IDH. Caso de la Comunidad Mayagna (Sumo) Awas Tingni Vs. Nicaragua. Fondo, Reparaciones y Costas. Sentencia de 31 de agosto de 2001. Serie C No. 79.

88 Los conceptos de familia y de religión se conectan íntimamente con el territorio tradicional, en donde los cementerios ancestrales, los lugares de significado e importancia religiosos y los patrones de parentesco se vinculan a la ocupación y uso de sus territorios físicos [CIDH, Informe No. 40/04, Caso 12.053, Comunidades Indígenas Mayas del Distrito de Toledo (Belice), 12 de octubre de 2004, párr. 155]. Por ello, al ser el territorio y los recursos naturales elementos integrantes de la cosmovisión, vida espiritual y forma de subsistencia de los pueblos indígenas y tribales, forman parte intrínseca del derecho de las personas que 
que, como enfatiza la CIDH, "la sociedad indígena se estructura en base a su relación profunda con la tierra" ${ }^{89}$, toda vez que la importancia reside en que "la tierra constituye para los pueblos indígenas una condición de la seguridad individual y del enlace del grupo" 90 (supervivencia cultural, mantenimiento de la integridad comunitaria).

Cuando nos referimos a la supervivencia cultural como bien jurídico protegido, la referencia es directa a las formas de transmisión de la cultura, puesto que la posesión y el uso y goce de los territorios son el factor determinante para esta transmisión de saberes, costumbres y vivencias culturales. En este sentido la Corte Interamericana ha señalado que "para las comunidades indígenas la relación con la tierra no es meramente una cuestión de posesión y producción sino un elemento material y espiritual del que deben gozar plenamente, inclusive para preservar su legado cultural y transmitirlo a las generaciones futuras". ${ }^{91}$ La pérdida de la posesión de la tierra acarrea consigo

Ios conforman a la identidad cultural [CIDH, Democracia y Derechos Humanos en Venezuela. Doc. OEA/Ser.L/V/II, Doc. 54, 30 de diciembre de 2009, párr. 1054].

$89 \mathrm{CIDH}$, Quinto Informe sobre la Situación de los Derechos Humanos en Guatemala. Doc. OEA/Ser.L/V/II.111, Doc. 21 rev., 6 de abril de 2001, Capítulo XI, párr. 56.

$90 \mathrm{CIDH}$, Segundo Informe sobre la Situación de los Derechos Humanos en el Perú. Doc. OEA/Ser.L/V/II.106, Doc. 59 rev., 2 de junio de 2000, Capítulo X, párr. 16.

91 Corte IDH. Caso de la Comunidad Mayagna (Sumo) Awas Tingni Vs. Nicaragua. Fondo, Reparaciones y Costas. Sentencia de 31 de agosto de 2001. Serie C No. 79, párr. 149. Corte IDH. Caso Comunidad Indígena Yakye Axa Vs. Paraguay. Fondo, Reparaciones y Costas. Sentencia 17 de junio de 2005. Serie C No. 125, párrs. 124, 131. Corte IDH. Caso Masacre Plan de Sánchez Vs. Guatemala. Reparaciones y Costas. Sentencia de 19 de noviembre 2004. Serie C No. 116, párr. 85. - "[L]a garantía del derecho a la propiedad comunitaria de los pueblos indígenas debe tomar en cuenta que la tierra está estrechamente relacionada con sus tradiciones y expresiones orales, sus costumbres y lenguas, sus artes y rituales, sus conocimientos y usos relacionados con la naturaleza, sus artes culinarias, el derecho consuetudinario, su vestimenta, filosofía y valores. En función de su entorno, su integración con la naturaleza y su historia, los miembros de las comunidades indígenas transmiten de generación en generación este patrimonio cultural inmaterial, que es recreado constantemente por los miembros de las comunidades y grupos indígenas", Corte IDH. Caso Comunidad Indígena Yakye Axa Vs. Paraguay. Fondo, Reparaciones y Costas. Sentencia 17 de junio de 2005. Serie C No. 125, párr. 154. 
el impedimento de transmisión de su patrimonio cultural inmaterial, que se haya imperiosamente ligado al ejercicio pleno del derecho de propiedad, siempre que la tierra se encuentra intimamente relacionada con sus tradiciones, expresiones orales, costumbres, lenguas, artes, rituales, conocimientos, derecho consuetudinario, vestimenta, filosofía y valores, entre otros.

En lo que respecta al derecho a la vida digna, este se encuentra intensamente relacionado con la propiedad comunitaria de la tierra, en tanto su violación, como expone la $\mathrm{CIDH}$ crea circunstancias típicas de pobreza; las cuales consecuentemente desencadenan violaciones transversales de los derechos humanos, como son las violaciones "a la integridad personal, a la existencia digna, a la alimentación, al agua, a la salud, a la educación y los derechos de los niños". ${ }^{92}$ La consecuencia directa de la privación de la posesión y uso de las tierras y los recursos naturales es la producción de condiciones de miseria para las comunidades, las cuales se ven impedidas de utilizar los bienes necesarios para su subsistencia, o de realizar sus actividades económico-productivas, como la caza, la pesca, la recolección o la agricultura, o hasta de acceder a sus sistemas tradicionales de salud, implicando todo ello en mayores índices de mortalidad y desnutrición infantil, y mayor vulnerabilidad a enfermedades y epidemias. ${ }^{33}$

$92 \mathrm{CIDH}$, Democracia y Derechos Humanos en Venezuela. Doc. OEA/Ser.L/V/II, Doc. 54, 30 de diciembre de 2009, párrs. 1076 1080. CIDH, Quinto Informe sobre la Situación de los Derechos Humanos en Guatemala. Doc. OEA/Ser.L/V/II.111, Doc. 21 rev., 6 de abril de 2001, párrs. 4448.

93 La falta de garantía por el Estado del derecho al territorio ancestral de las comunidades indígenas puede implicar incumplimiento del deber de garantizar la vida de sus miembros; tal fue el caso de la comunidad Yakye Axa: "el Estado, al no garantizar el derecho de la comunidad a su territorio ancestral, ha incumplido el deber de garantizar la vida de sus miembros, ya que ha privado a la comunidad de sus medios de subsistencia tradicionales, obligándola durante años a sobrevivir en condiciones deplorables y dejándola a merced de acciones de asistencia estatal". [CIDH, Alegatos ante la Corte Interamericana de Derechos Humanos en el caso de Yakye Axa v. Paraguay. Referidos en: Corte IDH. Caso Comunidad Indígena Yakye Axa Vs. Paraguay. Fondo, Reparaciones y Costas. Sentencia de 17 de junio de 2005. Serie C No. 125, párr. 157(b).] 
El derecho a la vida digna ${ }^{94}$, en tanto derecho fundamental cuyo goce pleno es prerrequisito para el disfrute de todos los restantes derechos humanos establecidos en la Convención Americana sobre Derechos Humanos, genera en cabeza del Estado la responsabilidad de generar condiciones de vida dignas, de no producir condiciones que obstaculicen la dignidad mínima de las personas, y de adoptar medidas positivas para satisfacer el derecho a la vida digna en situaciones de vulnerabilidad y riesgo. ${ }^{95}$

En lo que respecta al derecho a la salud, como se ha señalado, las comunidades indígenas dependen de los recursos naturales y del suelo para "la práctica de la medicina tradicional de prevención y cura de enfermedades" 96 , siendo nuevamente el uso y goce de sus territorios de esencial importancia para la satisfacción de este derecho. ${ }^{97}$

94 El derecho a la vida digna "comprende no sólo el derecho de todo ser humano de no ser privado de la vida arbitrariamente, sino también el derecho a que no se generen condiciones que le impidan o dificulten el acceso a una existencia digna", Corte IDH. Caso Comunidad Indígena Yakye Axa Vs. Paraguay. Fondo, Reparaciones y Costas. Sentencia 17 de junio de 2005. Serie C No. 125, párr. 161. Corte IDH. Caso de los Hermanos Gómez Paquiyauri Vs. Perú. Fondo, Reparaciones y Costas. Sentencia de 8 de julio de 2004. Serie C No. 110 , párr. 128. Corte IDH. Caso "Instituto de Reeducación del Menor" Vs. Paraguay. Excepciones Preliminares, Fondo, Reparaciones y Costas. Sentencia de 2 de septiembre de 2004. Serie C No. 112, párr. 156. Corte IDH. Caso Myrna Mack Chang Vs. Guatemala. Fondo, Reparaciones y Costas. Sentencia de 25 de noviembre de 2003. Serie C No. 101, párr. 152. Corte IDH. Caso de los "Niños de la Calle" (Villagrán Morales y otros) Vs. Guatemala. Fondo. Sentencia de 19 de noviembre de 1999. Serie C No. 63, párr. 144.

95 Corte IDH. Caso "Instituto de Reeducación del Menor" Vs. Paraguay. Excepciones Preliminares, Fondo, Reparaciones y Costas. Sentencia de 2 de septiembre de 2004. Serie C No. 112, párr. 159.

96 Corte IDH. Caso Comunidad Indígena Yakye Axa Vs. Paraguay. Fondo, Reparaciones y Costas. Sentencia de 17 de junio de 2005. Serie C No. 125, párr. 168.

97 "La Corte Interamericana ha retomado lo dispuesto por el Comité de Derechos Económicos, Sociales y Culturales de la ONU en su Observación General No. 14 sobre el derecho al disfrute del más alto nivel posible de salud, según el cual "los pueblos indígenas tienen derecho a medidas específicas que les permitan mejorar su acceso a los servicios de salud y a las atenciones de la salud. Los servicios de salud deben ser apropiados desde el punto de vista cultural, es decir, tener en cuenta los cuidados preventivos, las prácticas curativas y las medicinas tradicionales (...). // Para las comunidades indígenas, la salud del individuo se 
En suma, la privación del derecho a la propiedad de la tierra y los recursos naturales genera una multiplicidad de violaciones de derechos humanos económicos, sociales y culturales, que la Corte subraya de la siguiente manera: "las afectaciones especiales del derecho a la salud, e íntimamente vinculadas con él, las del derecho a la alimentación y el acceso a agua limpia impactan de manera aguda el derecho a una existencia digna y las condiciones básicas para el ejercicio de otros derechos, como el derecho a la educación o el derecho a la identidad cultural"98, identidad cultural que se define por la posesión, uso y goce mismo de los territorios ancestrales y los recursos, constituyendo su forma de vida particular. ${ }^{99}$ La falta de garantía del derecho a la propiedad comunitaria, por lo tanto, perjudica la preservación de las formas de vida, costumbres e idioma de las comunidades indígenas y tribales.

Disponer la pérdida del territorio ancestral implica impeler a los pueblos indígenas a asimilarse con las sociedades occidentales modernas, mediando la pérdida de su identidad. La Corte imprime al respecto de manera cabal que "la posesión de su territorio tradicional está marcada de forma indeleble en su memoria histórica y la relación que mantienen con la tierra es de una calidad tal que su desvinculación de la misma implica riesgo cierto de una pérdida étnica y cultural irreparable,

\footnotetext{
suele vincular con la salud de la sociedad en su conjunto y presenta una dimensión colectiva. A este respecto, el Comité considera que (...) la (...) pérdida por esas poblaciones de sus recursos alimenticios y la ruptura de su relación simbiótica con la tierra, ejercen un efecto perjudicial sobre la salud de esas poblaciones"". [Comité de Derechos Económicos, Sociales y Culturales de la ONU, Observación General 14, párr. 27, citada en: Corte IDH. Caso Comunidad Indígena Yakye Axa Vs. Paraguay. Fondo, Reparaciones y Costas. Sentencia de 17 de junio de 2005. Serie C No. 125, párr. 166].

98 Corte IDH. Caso Comunidad Indígena Yakye Axa Vs. Paraguay. Fondo, Reparaciones y Costas. Sentencia de 17 de junio de 2005. Serie C No. 125, párr. 167.

99 Sólo por citar uno de los tantos ejemplos que pudieren darse, "Ios cementerios ancestrales, los lugares de significado e importancia religiosos y los sitios ceremoniales o rituales vinculados a la ocupación y uso de sus territorios físicos constituyen un elemento intrínseco del derecho a la identidad cultural", CIDH, Informe No. 40/04, Caso 12.053, Comunidades Indígenas Mayas del Distrito de Toledo (Belice), 12 de octubre de 2004, párr. 155.
} 
con la consecuente vacante para la diversidad que tal hecho acarrearía" ${ }^{100}$. Esta pérdida de identidad cultural, en consecuencia de la falta de acceso a la tierra ancestral, surte un impacto inmediato en los niños y niñas indígenas, quienes se ven privados de su derecho a vivir de acuerdo con su propia cultura, su propia religión y su propio idioma, que se encuentra garantizado por la Convención sobre los Derechos del Niño (artículo 30), y en consonancia con el artículo 19 de la Convención Americana. ${ }^{101}$

Los derechos laborales de los integrantes de los pueblos indígenas son igualmente vulnerados, toda vez que la pérdida de los territorios ancestrales implica la privación del acceso a las actividades tradicionales de subsistencia que las comunidades realizan. Ello expone a los miembros de los grupos a situaciones de explotación laboral (jornadas laborales excesivas, violencia, intimidación, entre otros), trabajo forzado o hasta la servidumbre por deudas en muchos casos, que constituyen formas contemporáneas de esclavitud; ${ }^{102}$ arrastrándolos a soportar malas condiciones de trabajo, salarios bajos y ausencia de seguridad social. ${ }^{103}$

100 Corte IDH. Caso Comunidad Indígena Yakye Axa Vs. Paraguay. Fondo, Reparaciones y Costas. Sentencia de 17 de junio de 2005. Serie C No. 125, párr. 216

101 En ese sentido, la Corte considera que "la pérdida de prácticas tradicionales, como los ritos de iniciación femenina o masculina y las lenguas de la Comunidad, y los perjuicios derivados de la falta de territorio, afectan en forma particular el desarrollo e identidad cultural de los niños y niñas de la Comunidad, quienes no podrán siquiera desarrollar esa especial relación con su territorio tradicional y esa particular forma de vida propia de su cultura si no se implementan las medidas necesarias para garantizar el disfrute de estos derechos", Corte IDH. Caso de la Comunidad Indígena Xákmok Kásek vs. Paraguay. Fondo, Reparaciones y Costas. Sentencia de 24 de agosto de 2010, Serie C No. 214, párrs. 261-263 [notas al pie omitidas].

${ }^{102} \mathrm{CIDH}$, Tercer Informe sobre la Situación de los Derechos Humanos en Paraguay. Doc. OEA/Ser./L/VII.110, Doc. 52, 9 de marzo de 2001, párrs. 35, 37, 40. CIDH, Acceso a la Justicia e Inclusión Social: El camino hacia el fortalecimiento de la Democracia en Bolivia. Doc. OEA/ Ser.L/V/II, Doc. 34, 28 de junio de 2007, párrs. 257-268, 297 - Recomendación 8.

103 Los resultados del informe de la Comisión sobre la situación del pueblo indígena Guaraní en el Chaco de Bolivia son los siguientes: la CIDH "constata la existencia de servidumbre por 


\section{Obligaciones estatales frente a los Pueblos Indígenas}

En este apartado se desarrollaran las obligaciones que recaen sobre los Estados en relación a la salvaguarda de los derechos de los pueblo indígenas. Primeramente, se abordaran las obligaciones generales que los Estados tienen para con los pueblos indígenas, en segundo término abordaremos las obligaciones que también generan responsabilidad internacional a los Estados Parte en conexión con las violaciones de derechos humanos entre particulares. Por último, se tratará la obligación que tienen los Estados de respetar determinadas garantías específicas a los pueblos indígenas en el contexto de actividades de extracción, explotación o desarrollo.

\section{i. Obligaciones generales de los Estados}

En lo que atañe a la responsabilidad de los Estados parte del sistema de protección de derechos humanos de la OEA, adherentes a la Convención Americana, podemos encontrar como obligación general primera la de respetar el artículo $1.1^{104}$

deudas y trabajo forzoso los cuales son prácticas que constituyen formas contemporáneas de esclavitud. Sin lugar a duda, familias y comunidades guaraníes viven sometidas a un régimen laboral en donde no tienen el derecho de definir las condiciones de empleo, tal como las horas de trabajo y el salario; trabajan jornadas laborales excesivas por un pago ínfimo, lo que contraviene la normativa laboral nacional; y además viven bajo amenaza de violencia, lo que también conduce a una situación de temor y absoluta dependencia del empleador. La Comisión resalta la importancia del hecho de que se trata de individuos, familias o comunidades pertenecientes a un pueblo indígena, que se encuentran en esa condición deplorable debido a la pérdida involuntaria de sus tierras ancestrales, como producto de acciones y políticas emprendidas por el Estado a lo largo de más de un siglo, y que en la actualidad ven imposibilitado el goce de sus derechos fundamentales, como pueblo indígena, con respecto a sus derechos a la propiedad comunal colectiva, acceso a justicia, a una vida digna y al desarrollo de su propio autogobierno y sus propias instituciones sociales, culturales y políticas", CIDH. Comunidades cautivas: Situación del pueblo indígena guaraní y formas contemporáneas de esclavitud en el Chaco de Bolivia. Doc. OEA/Ser.L/V/II.I, Doc. 58, 24 de diciembre de 2009, párr. 166.

104 “Artículo 1. Obligación de Respetar los Derechos / 1. Los estados partes se comprometen a resptera los derechos y libertades reconocidos en ella y a garantizar su libre y pleno ejercicio a toda persona que esté sujeta a su jurisdicción, sin discriminación alguna por motivos 
de la Convención. El mismo impone la obligación de respetar y garantizar los derechos humanos a todas las personas que se encuentran dentro de la jurisdicción del Estado, así como también la de no discriminación (sea esta de cualquier índole).

En adición, reviste carácter de suma importancia el artículo $2^{105}$ de la Convención, en tanto este establece la obligación general de adecuar el ordenamiento interno a las normas de la Convención Americana. La importancia antes mencionada recae en el llamado principio de effet utile ${ }^{106}$ que consagra dicho artículo. En razón del nombrado principio, cada Estado Parte debe adecuar su derecho interno a las disposiciones contenidas en la Convención, con la finalidad de garantizar los derechos contenidos en ella, dotándolos de efectividad. Lo que este deber implica para los Estados es la supresión de normas y prácticas que supongan violaciones a las garantías previstas por la Convención, y, por otro lado, la expedición de normas y el desarrollo de prácticas que conduzcan a la efectiva observancia de dichas garantías.

Cuando fue turno de la CIDH de analizar esta obligación estatal en relación a los derechos de los pueblos indígenas, la

de raza, color, sexo, idioma, religión, opiniones políticas o de cualquier otra índole, origen nacional o social, posición económica, nacimiento o cualquier otra condición social. [...]" [Convención Americana sobre Derechos Humanos (Pacto San José de Costa Rica)"; suscripta en la Conferencia Especializada Interamericana sobre Derechos Humanos, San José, Costa Rica 7 al 22 de noviembre de 1969].

105 “Artículo 2. Deber de Adoptar Disposiciones de Derecho Interno. Si el ejercicio de los derechos y libertades mencionados en el artículo 1 no estuviere ya garantizado por disposiciones legislativas o de otro carácter, los Estados Partes se comprometen a adoptar, con arreglo a sus procedimientos constitucionales y a las disposiciones de esta Convención, las medidas legislativas o de otro carácter que fueren necesarias para hacer efectivos tales derechos y libertades. [Convención Americana sobre Derechos Humanos (Pacto San José de Costa Rica)"; suscripta en la Conferencia Especializada Interamericana sobre Derechos Humanos, San José, Costa Rica 7 al 22 de noviembre de 1969].

${ }^{106}$ Corte IDH. Caso "La Última Tentación de Cristo" (Olmedo Bustos y otros) Vs. Chile. Fondo, Reparaciones y Costas. Sentencia de 5 de febrero de 2001. Serie C No. 73, párr. 87; y Caso Heliodoro Portugal Vs. Panamá. Excepciones Preliminares, Fondo, Reparaciones y Costas. Sentencia de 12 de agosto de 2008. Serie C No. 186, párr. 179. 
misma destacó que la legislación jurídicamente favorable "por sí sola no puede garantizar los derechos de estos pueblos" 107 , y prosiguió aseverando que un marco jurídico favorable "no es suficiente para la debida protección de sus derechos si no está acompañad[o] de políticas y acciones estatales que velen por la aplicación y cumplimiento efectivo de las normas a las que el propio Estado soberanamente se ha obligado" ${ }^{108}$, como son la inclusión de " medidas que promuevan la plena efectividad de sus derechos sociales, económicos y culturales, respetando su identidad social y cultural, sus costumbres, tradiciones e instituciones"109, o también la aplicación de "mecanismos adecuados de control y seguimiento para monitorear el desempeño de las autoridades estatales y asegurar, así, el disfrute efectivo de los derechos y garantías". 110

Por su parte, la Corte ha insistido en que es obligación de los Estados la de garantizar "la existencia, en la realidad, de una eficaz garantía del libre y pleno ejercicio de los derechos humanos"111, en razón de que los pueblos indígenas y tribales tienen derecho a que las normas de derecho interno sean

${ }^{107} \mathrm{CIDH}$, Alegatos ante la Corte Interamericana de Derechos Humanos en el caso de Sawhoyamaxa v. Paraguay. Referidos en: Corte IDH. Caso Comunidad Indígena Sawhoyamaxa Vs. Paraguay. Fondo, Reparaciones y Costas. Sentencia de 29 de marzo de 2006. Serie C No. 146, párr. 113(b).

${ }^{108} \mathrm{CIDH}$, Alegatos ante la Corte Interamericana de Derechos Humanos en el caso de Yakye Axa v. Paraguay. Referidos en: Corte IDH. Caso Comunidad Indígena Yakye Axa Vs. Paraguay. Fondo, Reparaciones y Costas. Sentencia de 17 de junio de 2005. Serie C No. 125, párr. 120(b). Ver también: CIDH, Quinto Informe sobre la Situación de los Derechos Humanos en Guatemala. Doc. OEA/Ser.L/V/II.111, Doc. 21 rev., 6 de abril de 2001, párr. 36. CIDH, Tercer Informe sobre la Situación de los Derechos Humanos en Paraguay. Doc. OEA/Ser./L/VII.110, Doc. 52, 9 de marzo de 2001, párr. 28.

${ }^{109} \mathrm{CIDH}$, Tercer Informe sobre la Situación de los Derechos Humanos en Paraguay. Doc. OEA/Ser./L/VII.110, Doc. 52, 9 de marzo de 2001, Capítulo IX, párr. 13.

${ }^{110} \mathrm{CIDH}$, Segundo Informe sobre la Situación de los Derechos Humanos en el Perú. Doc. OEA/Ser.L/V/II.106, Doc. 59 rev., 2 de junio de 2000, Capítulo X, párr. 39 - Recomendación 3.

111 Corte IDH. Caso Comunidad Indígena Sawhoyamaxa Vs. Paraguay. Fondo, Reparaciones y Costas. Sentencia de 29 de marzo de 2006. Serie C No. 146, párr. 167. Corte IDH. Caso de la Masacre de Pueblo Bello Vs. Colombia. Fondo, Reparaciones y Costas. Sentencia de 31 de enero de 2006. Serie C No. 140, párr. 142. 
implementadas y aplicadas en la práctica. Es también jurisprudencia de la Corte que los pueblos indígenas deben ostentan una protección especial en razón de la mayor vulnerabilidad de estos grupos, por las condiciones de marginación y discriminación históricas que han sufrido. ${ }^{112}$

\section{ii. Obligaciones estatales de derechos humanos entre particulares}

Como es de notorio conocimiento, la realidad demuestra que a nivel regional, gran parte de los proyectos de naturaleza extractiva, de explotación o desarrollo tienen lugar en tierras tradicionalmente ocupadas por pueblos indígenas, en razón de los recursos naturales que las mismas albergan o por la ubicación estratégica en la cual se posicionan. También es sabido que muchas de estas actividades no son llevadas a cabo siempre por los Estados, sino que revisten a veces inversiones de carácter mixto (público-privado) o son llevadas a cabo por terceros (empresas privadas). Sin embargo, el sistema interamericano de protección de derechos humanos ha reconocido, en múltiples ocasiones y en determinadas circunstancias, que los actos violatorios de derechos humanos cometidos por terceros pueden generar responsabilidad internacional del Estado Parte y serles atribuibles.

La regla general que sostiene la Corte importa que "es imputable al Estado toda violación a los derechos reconocidos por la Convención cumplida por un acto del poder público o de personas que actúan prevalidas de los poderes que ostentan por su carácter oficial [...]"; aunque, siguiendo la línea que se presenta, "no se agotan allí las situaciones en las cuales un Estado está obligado a prevenir, investigar y sancionar las violaciones a los derechos humanos, ni los supuestos en que su responsabilidad puede verse comprometida por efecto de una lesión a esos

\footnotetext{
$112 \mathrm{CIDH}$, Observaciones preliminares de la Comisión Interamericana de Derechos Humanos sobre su visita a Honduras realizada del 15 al 18 de mayo de 2010. Doc. OEA/Ser.L/V/II., Doc. 68, 3 de junio de 2010. Parr. 26, Recomendación No. 11.
} 
derechos. En efecto, un hecho ilícito violatorio de los derechos humanos que inicialmente no resulte imputable directamente a un Estado, por ejemplo, por ser obra de un particular o por no haberse identificado al autor de la trasgresión, puede acarrear la responsabilidad internacional del Estado, no por ese hecho en sí mismo, sino por falta de la debida diligencia para prevenir la violación o para tratarla en los términos requeridos por la Convención". ${ }^{113}$

Ahora bien, la fundamentación de dicha responsabilidad tiene asidero en que"[1]as obligaciones del Estado proyectan sus efectos más allá de la relación entre sus agentes y las personas sometidas a su jurisdicción, pues se manifiestan también en la obligación positiva del Estado de adoptar las medidas necesarias para asegurar la efectiva protección de los derechos humanos en las relaciones inter-individuales"114, como explica con sus palabras la Corte. Empero, ello no implica una responsabilidad ilimitada de los Estados frente a los actos o hechos de particulares, sino que se relaciona con las obligaciones que los Estados tienen de adoptar medidas de prevención y protección de derechos humanos en las relaciones entre los particulares, cuando estos tuvieren "conocimiento de una determinada situación de riesgo real e inmediato para un individuo o grupo de individuos determinado y a las posibilidades razonables de prevenir o evitar ese riesgo". ${ }^{115}$

Encuadrando con lo hasta aquí expuesto, la doctrina del sistema de protección de derechos humanos de la ONU (Comité de Derechos Humanos, encargado de evaluar el cumplimiento del Pacto Internacional de Derechos Civiles y Políticos), ha señalado

\footnotetext{
${ }^{113}$ Corte IDH. Caso Velásquez Rodríguez Vs. Honduras. Fondo. Sentencia de 29 de julio de 1988. Serie C No. 4. párr. 172; y Caso Godínez Cruz Vs. Honduras. Fondo. Sentencia de 20 de enero de 1989. Serie C No. 5. párrs. 181, 182 y 187.

114 Corte IDH. Caso de la "Masacre de Mapiripán" Vs. Colombia. Sentencia de 15 de septiembre de 2005, Serie C No. 134. párrs. 111 y 112.

115 Corte IDH. Caso de la Masacre de Pueblo Bello Vs. Colombia. Sentencia de 31 de enero de 2006. Serie C No. 140. párr. 123.
} 
que: "las obligaciones positivas de los Estados Partes de velar por los derechos del Pacto sólo se cumplirán plenamente si los individuos están protegidos por el Estado, no sólo contra las violaciones de los derechos del Pacto por sus agentes, sino también contra los actos cometidos por personas o entidades privadas que obstaculizarían el disfrute de los derechos del Pacto en la medida en que son susceptibles de aplicación entre personas o entidades privadas". ${ }^{116}$ En consonancia, el Comité de Derechos Económicos, Sociales y Culturales, en el marco del Pacto Internacional de Derechos Económicos, Sociales y Culturales, ha adoptado la misma postura. ${ }^{117}$

iii. Obligaciones especificas de los Estados y garantías de los pueblos indígenas en el contexto de actividades de extracción, explotación o desarrollo

Si bien la CIDH advierte la importancia que el desarrollo económico reviste para la prosperidad de los pueblos americanos, toda vez que "reconoce que el derecho al desarrollo implica que cada Estado tiene la libertad de explotar sus recursos naturales, incluyendo [el otorgamiento] de concesiones y la apertura a inversiones internacionales"118, sostiene, de todas formas que "las actividades de desarrollo deben ir acompañadas de medidas adecuadas y efectivas para garantizar que las mismas no se lleven a cabo a expensas de los derechos

\footnotetext{
${ }^{116}$ ONU. Comité de Derechos Humanos. Observación General No. 31: La índole de la obligación jurídica general impuesta a los Estados Partes en el Pacto. U.N. Doc. CCPR/C/21/Rev.1/ Add.13 26 de mayo de 2004. párr.8.

117 Por ejemplo, en su Observación General No. 12 Comité de Derechos Económicos, Sociales y Culturales afirmó que "[...][l]a obligación de proteger requiere que el Estado Parte adopte medidas para velar por que las empresas o los particulares no priven a las personas del acceso a una alimentación adecuada". Véase ONU. Comité de Derechos Económicos, Sociales y Culturales. Observación General No. 12: Aplicación del Pacto Internacional de Ios Derechos Económicos, Sociales y Culturales, El derecho a una alimentación adecuada (artículo 11). U.N. Doc. E/C.12/1999/5 (1999). párr. 15.

${ }^{118} \mathrm{CIDH}$. Informe sobre la Situación de los Derechos Humanos en Ecuador. Capítulo VIII. OEA/SerieL/V/II.96, doc. 10 rev. 1, 24 de abril de 1997.
} 
humanos de las personas que pueden ser particular y negativamente afectadas". 119

Es factible observar que, de esta forma, el sistema interamericano no desalienta el desarrollo económico de los Estados Parte, lo cual no significa que por ello no establezca las condiciones que deban ser respetadas y garantizadas en los procesos de explotación o desarrollo. Condiciones que tienen por objetivo salvaguardar los derechos de la comunidad en su totalidad, como ser el derecho medioambiental, pero que son de extrema relevancia para el caso de las comunidades indígenas. ${ }^{120}$

Cuando son los Estados los que implementan proyectos extractivos o de explotación, los Estados tienen obligaciones directas de respetar los derechos humanos de los actores involucrados (véase en el caso que nos atañe, los pueblos indígenas); pero, como ya se ha visto, cuando son terceros los que realizan tales actividades, los Estados también tienen obligaciones específicas que cumplir.

Dichas obligaciones específicas (aplicables a la generalidad de los casos y no únicamente para el de los territorios de propiedad comunal indígena) que tiene los Estados Parte en el contexto de actividades de extracción, explotación o desarrollo son, según la CIDH las siguientes: (i) el deber de adoptar un marco normativo adecuado y efectivo, (ii) el deber de prevenir las violaciones de derechos humanos, (iii) la obligación de supervisar y fiscalizar las actividades de las empresas y otros actores no estatales, (iv) el deber de garantizar mecanismos de

\footnotetext{
${ }^{119} \mathrm{CIDH}$. Comunidades indígenas Mayas del distrito de Toledo (Belice), Informe de Fondo No. 40/04, Caso 12.053, 12 de octubre de 2004. párr. 150.

${ }^{120} \mathrm{CIDH}$. Informe sobre la Situación de los Derechos Humanos en Ecuador. Capítulo VIII. OEA/SerieL/V/II.96, doc. 10 rev. 1, 24 de abril de 1997. En similar sentido, la Declaración de Principios de la Cumbre de las Américas señala que "El progreso social y la prosperidad económica solo se pueden mantener si nuestros pueblos viven en un entorno saludable y nuestros ecosistemas y recursos naturales se utilizan cuidadosamente y de manera responsable". Primera Cumbre de las Américas. Declaración de Principios: Pacto para el Desarrollo y la Prosperidad: Democracia, Libre Comercio y Desarrollo Sostenible en las Américas. Miami, Florida, 9 al 11 de diciembre de 1994.
} 
participación efectiva y acceso a la información, (v) el deber de prevenir actividades ilegales y formas de violencia, y (vi) el deber de garantizar el acceso a la justicia a través de la investigación, sanción y reparación adecuada de las violaciones de derechos humanos en estos contextos. ${ }^{121}$

En adición a las mencionadas pautas que establece la $\mathrm{CIDH}$ en relación a las obligaciones estatales en contextos de las referidas actividades, de forma específica establece también un conjunto de requisitos que deben ser cumplidos por los Estados "[a] los efectos de otorgar concesiones extractivas o de realizar planes y proyectos de desarrollo, explotación y extracción que afecten los recursos naturales en territorios indígenas o tribales, la Corte Interamericana ha identificado tres condiciones obligatorias que se aplican cuando los Estados contemplen aprobar tales planes o proyectos: (a) el cumplimiento del derecho internacional sobre la expropiación, tal y como se refleja en el artículo 21 de la Convención Americana; (b) no aprobación de cualquier proyecto que pueda amenazar la supervivencia física o cultural del grupo; y (c) aprobación sólo después de asegurar su participación efectiva - incluyendo, cuando sea aplicable, el consentimiento- de un estudio previo de impacto ambiental y social realizado con participación indígena, y con participación razonable en los beneficios". ${ }^{122}$

A su vez, la CIDH estableció determinadas garantías que ostentan los pueblos indígenas en el contexto de actividades extractivas o de explotación realizadas en sus territorios ancestrales. Estas garantías deben ser respetadas por los Estados Parte, que deben asegurar su cumplimiento aun cuando las actividades productivas estén dirigidas por particulares. La primera de ellas

\footnotetext{
121 Comisión Interamericana de Derechos Humanos; “Pueblos indígenas, comunidades afrodescendientes y recursos naturales: protección de derechos humanos en el contexto de actividades de extracción, explotación y desarrollo"; OEA/Ser.L/V/II. Doc. 47/15 31 diciembre 2015; párr. 65; Disponible en: http://www.oas.org/es/cidh/informes/pdfs/IndustriasExtractivas2016.pdf ${ }^{122} \mathrm{CIDH}$. Derechos de los pueblos indígenas y tribales sobre sus tierras ancestrales y recursos naturales. Normas y jurisprudencia del sistema Interamericano de derechos humanos. OEA/Ser.L/N/II, 30 de diciembre de 2009, párr. 225.
} 
es el (a) Deber de asegurar que las restricciones al uso y goce de las tierras, territorios y recursos naturales de los pueblos indígenas no impliquen una denegación de su supervivencia física y cultural. ${ }^{123}$ La segunda garantía es la de (b) Participación efectiva, estudios de impacto socio ambiental y beneficios compartidos. Esta garantía incluye el derecho a la consulta y consentimiento previo, libre e informado de los pueblos afectados; así como también la realización de un estudio previo de impacto social y ambiental, llevado a cabo por "entidades independientes y técnicamente capaces, bajo la supervisión del Estado" 124 que responde a la finalidad última de "preservar, proteger y garantizar la relación especial de los pueblos indígenas con sus territorios y garantizar su subsistencia como pueblos". ${ }^{125}$ Por otra parte, esta garantía también incumbe el derecho a la participación razonable en los beneficios del proyecto, que implica la implementación de "mecanismos de participación en los beneficios del proyecto a favor de las comunidades o pueblos afectados por la extracción de recursos naturales o los planes o proyectos de desarrollo o extracción". ${ }^{126}$

\footnotetext{
123 Ello implica que "el otorgamiento de la concesión no afecte la supervivencia del pueblo indígena o tribal de conformidad con sus modos ancestrales de vida".En términos de la Corte Interamericana, "otro factor crucial a considerar es también si la restricción implica una denegación de las tradiciones y costumbres de un modo que ponga en peligro la propia subsistencia del grupo y de sus integrantes". Corte IDH. Caso del Pueblo Saramaka. Vs. Suriname. Excepción Preliminar, Fondo, Reparaciones y Costas. Sentencia de 28 de noviembre de 2007. Serie C No. 172. parr. 128 y Caso Pueblo Indígena Kichwa de Sarayaku Vs. Ecuador. Fondo y reparaciones. Sentencia de 27 de junio de 2012. Serie C No. 245. párr. 156.
}

124 Corte IDH. Caso del Pueblo Saramaka. Vs. Surinam. Excepciones Preliminares, Fondo, Reparaciones y Costas. Sentencia de 28 de noviembre de 2007. Serie C No. 172, párr. 129. Corte IDH. Caso Pueblo Indígena Kichwa de Sarayaku Vs. Ecuador. Fondo y reparaciones. Sentencia de 27 de junio de 2012. Serie C No. 245. párr. 205.

${ }^{125}$ Corte IDH. Caso del Pueblo Saramaka Vs. Surinam. Interpretación de la Sentencia de Excepciones Preliminares, Fondo, Reparaciones y Costas. Sentencia de 12 de agosto de 2008 Serie C No. 185, párr. 40. CIDH, Acceso a la Justicia e Inclusión Social: El camino hacia el fortalecimiento de la Democracia en Bolivia. Doc. OEA/Ser.L/N/II, Doc. 34, 28 de junio de 2007, párr. 254.

${ }^{126} \mathrm{CIDH}$, Democracia y Derechos Humanos en Venezuela, 2009. Doc. OEA/Ser.L/V/II, Doc. 54, 30 de diciembre de 2009, párr. 1137, Recomendaciones 5 y 6; CIDH, Acceso a la Justicia 


\section{Violaciones a los derechos humanos e impacto en el pleno goce de los DESC de los Pueblos Indígenas en contextos de actividades extractivas, de explotación y desarrollo}

A lo largo de este apartado se desarrollarán los impactos negativos y las violaciones de derechos humanos que en la realidad existen en los contextos de actividades extractivas, de explotación o desarrollo, perpetuados por los Estados y/o por los particulares a cargo de dichas actividades. Esta problemática ha instado a la $\mathrm{CIDH}$, en virtud de la preocupante situación de los pueblos americanos, a la realización de una evaluación exhaustiva sobre estos impactos sociales, culturales y medioambientales. Como finalidad, se intentará generar un mayor acercamiento a la problemática de los derechos de propiedad comunitaria de los pueblos indígenas, mediante la ilustración de casos puntuales y la exposición de resultados estadísticos recogidos por la Comisión en el escenario de las violaciones de derechos humanos de estos pueblos. Los datos reunidos han llegado a $\mathrm{CIDH}$ por medio de distintos mecanismos, como son casos contenciosos, medidas cautelares, audiencias públicas, visitas oficiales realizadas por la Comisión seguidas de informes de país o comunicados de prensa, entre otros; y que han permitido a numerosos pueblos indígenas dar a conocer las afectaciones de sus derechos como consecuencia de la implementación de proyectos de esta naturaleza.

En uno de sus últimos informes sobre los Derechos de los pueblos indígenas y tribales sobre sus tierras ancestrales y recursos naturales, la $\mathrm{CIDH}$ ha afirmado que: "Los megaproyectos de infraestructura o desarrollo, tales como carreteras, canales, represas, puertos o afines, así como las concesiones para la exploración o explotación de recursos naturales en territorios ancestrales, pueden afectar a las poblaciones indígenas con consecuencias particularmente graves, ya que ponen en peligro sus

e Inclusión Social: El camino hacia el fortalecimiento de la Democracia en Bolivia. Doc. OEA/ Ser.L/N/II, Doc. 34, 28 de junio de 2007, párr. 248 y 297, Recomendaciones 5 y 6. 
territorios y los ecosistemas que allí se encuentran, por lo cual representan un peligro mortal para su supervivencia en tanto pueblos, especialmente en los casos en que la fragilidad ecológica de sus territorios coincide con su debilidad demográfica"127, lo que no hace más que demostrar como las violaciones de sus derechos generan un escenario que profundiza la situación de desprotección y pobreza extrema en la que se encuentran muchas comunidades, y que data de un largo recorrido histórico.

Los impactos que causan las actividades mineras, madereras y petroleras, entre otras, fueron individualizados por la $\mathrm{CIDH}$ en, principalmente, la disminución de la cantidad y calidad de fuentes de agua, el empobrecimiento de suelos agrícolas, la alteración de los sistemas de producción propios, la disminución de la pesca, fauna, flora y biodiversidad en general, y la afectación al equilibrio que constituye la base de la reproducción étnica y cultural de los pueblos indígenas. Siendo de especial preocupación para la misma que, "en ocasiones, las concesiones o proyectos se superponen a casi la integralidad del territorio ancestral de los pueblos indígenas"128 y, "que [los mismos] son autorizados en abierta contravención con la concepción de desarrollo propia de estos pueblos". ${ }^{129}$

Por otra parte, la $\mathrm{CIDH}$ ha tomado conocimiento, por medio de constantes denuncias de los pueblos originarios y/o

${ }^{127} \mathrm{CIDH}$. Derechos de los pueblos indígenas y tribales sobre sus tierras ancestrales y recursos naturales. Normas y jurisprudencia del sistema Interamericano de derechos humanos. OEA/Ser.L/V/II, 30 de diciembre de 2009. párr. 205.

${ }^{128} \mathrm{CIDH}$. Audiencia sobre el derecho de los pueblos indígenas a la personalidad jurídica y a la propiedad en Perú, 153 Período Ordinario de Sesiones, 31 de octubre de 2014; Audiencia sobre el derecho a la consulta previa de los pueblos indígenas en Ecuador, $149^{\circ}$ Período de Sesiones, 28 de octubre de 2013; y Audiencia sobre Denuncias sobre destrucción de la herencia biocultural de México por la construcción de mega proyectos de desarrollo en México. 153 Período Ordinario de Sesiones, 30 de octubre de 2014.

${ }^{129} \mathrm{CIDH}$. Audiencia sobre Situación de derechos humanos de los pueblos indígenas en el contexto del proceso de paz en Colombia. 149 Período de Sesiones, 31 de octubre de 2013; y Audiencia sobre Situación de derechos humanos del pueblo Asháninka en Perú, 138 Período de Sesiones, 23 de marzo de 2010. 
de organizaciones de protección de derechos humanos que "por motivos vinculados a los intereses de terceros en las tierras y territorios indígenas o tribales, los Estados no estarían cumpliendo con su obligación de reconocer, titular, delimitar y demarcar estos territorios, deberes ampliamente desarrollados por los órganos del sistema interamericano" ${ }^{\prime 30}$. Como así también, que en aquellos procesos de titulación que se encuentran abiertos, los Estados no estarían respetando la garantía del plazo razonable ${ }^{131} ;$ y de igual modo estarían faltando a su obligación de protegerlos frente a terceros ${ }^{132}$, favoreciendo, de forma contraria, los intereses de las empresas en el otorgamiento de concesiones o permisos, sin dar cumplimiento adecuado de las obligaciones de consulta previa e informada a los pueblos indígenas. Entre algunos de los ejemplos podríamos citar, "la obtención de títulos individuales superpuestos, la nulidad de títulos colectivos, la imposición de servidumbres administrativas e incluso, el uso de la violencia bajo la aquiescencia de los Estados"133, como mecanismos usuales de evadir sus

\footnotetext{
${ }^{130} \mathrm{CIDH}$. Audiencia sobre dificultades legales para el reconocimiento y titulación de tierras indígenas en Guatemala, $140^{\circ}$ Período de Sesiones, 25 de octubre de 2010. CIDH. Informe sobre la situación de los derechos humanos en Brasil. Capítulo VI. Los derechos humanos de los pueblos indígenas en Brasil. OEA/Ser.L/V/II.97, Doc. 29 rev.1, 29 septiembre 1997, párr. 62; y Audiencia sobre el Derecho a la propiedad privada de los pueblos indígenas en Panamá, $133^{\circ}$ Período de Sesiones, 28 de octubre de 2008.

${ }^{131} \mathrm{CIDH}$. Audiencia sobre el Derecho de los pueblos indígenas a la personalidad jurídica y a la propiedad en Perú, $153^{\circ}$ Período Ordinario de Sesiones, 31 de octubre de 2014; y Audiencia sobre Denuncias de ocupación de los territorios de los pueblos indígenas en Costa Rica, $147^{\circ}$ Período de Sesiones, 16 de marzo de 2013.
}

${ }^{132} \mathrm{CIDH}$. Audiencia sobre Situación de derechos humanos de los pueblos indígenas en Nicaragua. $150^{\circ}$ Período Ordinario de Sesiones, 25 de marzo de 2014; y Audiencia Caso 12.548 - Comunidad Garífuna Triunfo de la Cruz, Honduras, $127^{\circ}$ Período de Sesiones, 2 de marzo de 2007.

${ }^{133} \mathrm{CIDH}$. Audiencia sobre dificultades legales para el reconocimiento y titulación de tierras indígenas en Guatemala, $140^{\circ}$ Período de Sesiones, 25 de octubre de 2010. CIDH. Audiencia sobre la situación de derechos humanos de los afrocaribeños, campesinos e indígenas del Cantón de Talamanca, Costa Rica, 140 Período de Sesiones, 28 de octubre de 2010. CIDH. Audiencia sobre la Situación de la propiedad comunal indígena en Nicaragua, $138^{\circ}$ Período de Sesiones, 23 de marzo de 2010. Audiencia sobre Denuncias de violación de derechos 
responsabilidades en el otorgamiento de los derechos de propiedad comunitaria.

Otra de las problemáticas que ha identificado la $\mathrm{CIDH}$ es que los Estados suelen limitar sus obligaciones de protección sobre los territorios indígenas solo a aquellas tierras que cuentan con reconocimiento formal, las que usualmente constituyen únicamente fracciones pequeñas de los territorios que las comunidades utilizan para el desarrollo de sus actividades de subsistencia. A su respecto, debe recordarse que "[1]as garantías de protección del derecho a la propiedad bajo los instrumentos interamericanos de derechos humanos pueden ser invocadas por los pueblos indígenas y tribales respecto de territorios que les pertenecen, pero que aún no han sido titulados formalmente, demarcados o delimitados por el Estado". ${ }^{134}$ De igual forma, la ocupación ilegal de los territorios ancestrales, las expropiaciones arbitrarias y los actos de intimidación o violencia contra los miembros de estos pueblos se suceden con frecuencia. ${ }^{135}$

humanos de pueblos indígenas en Costa Rica. $153^{\circ}$ Período Ordinario de Sesiones, 31 de octubre de 2014.

${ }^{134} \mathrm{CIDH}$. Derechos de los pueblos indígenas y tribales sobre sus tierras ancestrales y recursos naturales. Normas y jurisprudencia del Sistema Interamericano de Derechos Humanos. OEA/Ser.L/V/II.Doc.56/09, 30 de diciembre de 2009, párr. 103. CIDH, Informe No. 40/04, Caso 12.053, Comunidades Indígenas Mayas del Distrito de Toledo (Belice), 12 de octubre de 2004, párr. 153.

135 Un ejemplo visible de ello es la construcción del denominado "Canal Interoceánico" en Nicaragua, por la cual la CIDH ha recibido múltiples denuncias, según las cuales "la concesión del proyecto fue otorgada sin licitación pública y sin consulta ni consentimiento de los pueblos indígenas y tribales afectados, quienes se verían privados de realizar sus principales actividades de autoconsumo, indispensables para la seguridad alimentaria de sus pueblos. Según se informó, sus territorios serían expropiados, afectando el $40 \%$ del territorio de los Pueblos Rama y Creole, bajo un marco legal que habría sido promulgado en contravención a los estándares interamericanos en la materia sobre pueblos indígenas con el objetivo de asegurar la viabilidad del proyecto", CIDH, Audiencia sobre la situación de derechos humanos de los pueblos indígenas en Nicaragua. $150^{\circ}$ Período Ordinario de Sesiones, 25 de marzo de 2014; y Audiencia sobre la situación de derechos humanos de las mujeres indígenas en Nicaragua. $153^{\circ}$ Período Ordinario de Sesiones. 28 de octubre de 2014. CIDH. Audiencia sobre la "Construcción del canal transoceánico y su impacto sobre los derechos humanos en Nicaragua", 154 Período de Sesiones, 16 de marzo de 2015. 
En lo que respecta a los pueblos indígenas en aislamiento voluntario, la $\mathrm{CIDH}$ resalta la omisión de los Estados en el cumplimiento de las garantías que los asisten, como ocurre en Bolivia y Brasil en el contexto de proyectos hidroeléctricos o madereros, por ejemplo. ${ }^{136}$

Dichas violaciones a las garantías de consulta y consentimiento de los pueblos indígenas han ocasionado también múltiples impactos en la identidad cultural y la libertad religiosa de los pueblos; en tanto, la imposición de proyectos de naturaleza extractiva o de explotación afectan el libre ejercicio de prácticas y ceremonias religiosas que son formas de expresión de la identidad cultural de los pueblos indígenas. "La Comisión ha identificado que los lugares sagrados o religiosos son afectados por encontrarse superpuestos con áreas donde se busca realizar actividades extractivas y de desarrollo". ${ }^{137}$ Esto podría implicar incluso la destrucción de los mismos como, por ejemplo, fue denunciado por algunos pueblos indígenas en México. Igualmente, la $\mathrm{CIDH}$ ha sido informada sobre el impedimento por parte de terceros del acceso a sitios sagrados y la interferencia en la libre realización de ceremonias religiosas.

En relación con la protección del derecho a la vida, la $\mathrm{CIDH}$ observó que "se han presentado asesinatos de líderes, lideresas o miembros de estos pueblos y comunidades en contextos de oposición a proyectos de esta naturaleza" ${ }^{138}$. Las investigaciones

\footnotetext{
136 "Los pueblos en aislamiento en Bolivia, por ejemplo, se encontrarían desprotegidos jurídicamente ante la ausencia de voluntad para garantizar sus derechos. En Brasil, los pueblos en aislamiento de los Ríos Madeira y Xingú se verían amenazados por hidroeléctricas, y por la presencia de madereros y garimpeiros (mineros ilegales) en sus territorios ancestrales", $\mathrm{CIDH}$, Audiencia sobre la situación de los pueblos en aislamiento voluntario en la Región Amazónica y el Gran Chaco, 141 Período de Sesiones, 25 de marzo de 2011.

${ }^{137} \mathrm{CIDH}$. Audiencia sobre Medidas Cautelares y Petición 592/07 - Hul'qumínum Treaty Group, Canadá, $133^{\circ}$ Período de Sesiones, 28 de octubre de 2008; y Audiencia sobre Petición 592/07 y Medidas Cautelares 110/07 - Hul'qumi'num Treaty Group, Canadá, 134 Período de Sesiones, 23 de marzo de 2009.

${ }^{138} \mathrm{CIDH}$. Audiencia sobre el Impacto de las actividades de empresas mineras canadienses sobre los derechos humanos en América Latina. $153^{\circ}$ Período Ordinario de Sesiones, 28 de
} 
de la Comisión ha revelado que, en su mayoría, los casos quedan impunes, y que con frecuencia son considerados como crímenes comunes, atribuidos a la violencia o a la inseguridad que existen en varios países; sumado a que los defensores de derechos humanos, al denunciar hechos violatorios, no reciben la protección suficiente ni necesaria por parte del Estado.

La salud, la integridad personal y la protección medioambiental se ven amenazadas constantemente. ${ }^{139}$ La contaminación del agua como producto de la actividad minera o agroindustrial conlleva un impacto en la salud de los pueblos indígenas de magnitudes alarmantes, a su respecto la $\mathrm{CIDH}$ expresa que "[l]a implementación de este tipo de proyectos puede suponer una seria contaminación por el vertimiento de sustancias - como mercurio- en el medio ambiente, bosques y ríos tradicionalmente utilizados por pueblos indígenas y tribales para su supervivencia física. Estas afectaciones pueden llegar a ser devastadoras en casos de proyectos mineros a gran escala o cuando se otorga un gran número de concesiones de pequeña escala sobre territorios indígenas"140. Asimismo, la CIDH observa "que entre los grupos más vulnerables a estas afectaciones se encuentran los niños y las mujeres en edad

octubre de 2014; Audiencia sobre la Situación de los derechos humanos de los pueblos indígenas en Argentina, 144 Período de Sesiones, 23 de marzo de 2012; y Audiencia la Situación de derechos humanos en la Amazonía peruana, $137^{\circ}$ Período de Sesiones, 3 de noviembre de 2009.

139 “En el caso de la minería, en particular, los impactos más frecuentemente reportados se refieren a la destrucción de ecosistemas donde se ubican las canteras, la remoción física de rocas, la afectación del sistema hidrológico, la contaminación del agua, explosiones, emisiones de polvo, entre otros. Asimismo, la CIDH ha sido informada sobre efectos nocivos en la salud de los pueblos indígenas debido a materiales químicos y tóxicos empleados para la extracción de minerales, sin las medidas de tratamiento necesarias", CIDH, Audiencia sobre Situación de derechos humanos de la comunidad indígena de Apetina en Surinam. 150 Período Ordinario de Sesiones. 27 de marzo de 2014.

${ }^{140} \mathrm{CIDH}$. Audiencia sobre el derecho de los pueblos indígenas a la personalidad jurídica y a la propiedad en Perú, $153^{\circ}$ Período Ordinario de Sesiones, 31 de octubre de 2014, y CIDH. Audiencia sobre Situación de derechos humanos de la comunidad indígena de Apetina en Surinam. 150 Período Ordinario de Sesiones. 27 de marzo de 2014. 
fértil"141; por ejemplo, el mercurio afecta al feto causando daños neurológicos para el niño o niña. El mismo, "que se deposita en ríos y otras fuentes de agua, se acumula en animales como el pescado que hacen parte de la dieta tradicional de muchas comunidades indígenas, tribales y afrodescendientes en la región. El consumo de alimentos con mercurio puede tener un serio impacto en la salud humana y puede exigir la sustitución de alimentos de la dieta tradicional lo que, en muchos casos, resulta sumamente difícil por motivos económicos y debido a la falta de alternativas factibles que pueda otorgar el Estado". ${ }^{142}$

Por otra parte, para el caso de proyectos petroleros, la Comisión observa que implican la apertura de trochas, evaluaciones sísmicas, y contaminación por derrames o pérdidas en la extracción. Los denominados proyectos, además de las obras para la extracción de los recursos naturales, requieren otras obras asociadas, como caminos o carreteras para asegurar el acceso. ${ }^{143} \mathrm{La} \mathrm{CIDH}$ ha recogido información sobre derrames en la selva amazónica debido a la rotura de oleoductos o tuberías generando, entre otros efectos, la presencia de cadmio en el agua por encima de los niveles permisibles, que no han sido reparados adecuadamente por los Estados. ${ }^{144}$

Las violaciones a los derechos territoriales y sobre sus recursos naturales, en el contexto de actividades de desarrollo, extractivas o de explotación, han causado consecuentemente violaciones de los derechos económicos y sociales de las

\footnotetext{
${ }^{141} \mathrm{CIDH}$. Audiencia sobre el derecho de los pueblos indígenas a la personalidad jurídica y a la propiedad en Perú, 153 Período Ordinario de Sesiones, 31 de octubre de 2014

${ }^{142} \mathrm{CIDH}$. Audiencia sobre Situación de derechos humanos de la comunidad indígena de Apetina en Surinam. 150 Período Ordinario de Sesiones. 27 de marzo de 2014.

${ }^{143} \mathrm{CIDH}$. Audiencia sobre los Derechos de los pueblos indígenas y política energética y extractiva en Perú, $140^{\circ}$ Período de Sesiones, 26 de octubre de 2010.

144 Un ejemplo de ello es la contaminación del río Marañón en Perú que trajo aparejados impactos en la salud de las comunidades indígenas afectadas, "quienes han manifestado que los peces del río estarían teniendo un olor y sabor desagradable", CIDH, Audiencia sobre los Derechos de los pueblos indígenas y política energética y extractiva en Perú, $140^{\circ}$ Período de Sesiones, 26 de octubre de 2010.
} 
comunidades, en tanto la privación de sus tierras constituye una privación extensiva de sus fuentes de subsistencia, y "amenaz[a] la seguridad alimentaria de las comunidades afectadas". ${ }^{145}$

Otra actividad que pone en riesgo la seguridad alimentaria de las poblaciones indígenas y su derecho a la salud es la utilización de semillas transgénicas, cuyo cultivo "exige altas cantidades de agrotóxicos, y los cuales son esparcidos mediante aeroplanos, aviones u otras maquinarias". ${ }^{146}$ Ello ocasiona la aspersión de sustancias tóxicas en comunidades adyacentes a los cultivos, afectando su salud y contaminando el medioambiente. A su respecto, la $\mathrm{CIDH}$ ha documentado mediante su informe anual del año 2015 que "las principales afectaciones al acceso al agua en las Américas derivan de los efectos negativos como consecuencia de la implementación de proyectos extractivos y del uso de agroquímicos en la Región, de la contaminación de las fuentes hídricas, de la falta de acceso al agua para personas y comunidades viviendo en pobreza y pobreza extrema, especialmente en zonas rurales, y por los cortes del servicio de provisión de agua potable, todo lo cual genera impactos desproporcionados en los derechos humanos de las personas, grupos y colectividades históricamente discriminadas". ${ }^{147}$

Por último, nos referiremos a la problemática del desplazamiento forzado, directamente relacionada con la instalación de actividades productivas en las tierras ancestrales indígenas. La CIDH imprime al respecto que "[e]l desplazamiento forzado de los pueblos indígenas y tribales fuera de sus tierras y territorios es una de las más graves consecuencias de la imposición de

\footnotetext{
145 Véase CIDH. Audiencia sobre la “Construcción del canal transoceánico y su impacto sobre los derechos humanos en Nicaragua", 154 Período de Sesiones, 16 de marzo de 2015.

${ }^{146} \mathrm{CIDH}$. Audiencia sobre la Situación de derechos económicos, sociales y culturales de campesinos en América Latina, 149 Período de Sesiones, 29 de octubre de 2013.

${ }^{147}$ CIDH, Informe Anual 2015, Capítulo IV.A - Acceso al Agua en las Americas: Una Aproximacion al Derecho Humano al Agua en el Sistema Interamericano. Información similar fue presentada durante la audiencia temática regional sobre derechos humanos y el gua en las Américas, celebrada durante el 156 Período de Sesiones de la CIDH, 23 de octubre del año 2015.
} 
proyectos que ha podido observar la Comisión"148, toda vez que "la implementación de proyectos de desarrollo, explotación o extracción requiere comúnmente de extensas áreas geográficas y exige muchas veces serias alteraciones a amplias cantidades de tierra para la construcción de diferentes tipos de edificaciones, plantas, instalaciones, la extensión de las vías de acceso y comunicación, entre otros". ${ }^{149}$ Estas alteraciones resultan abiertamente incompatibles con los usos que estos pueblos dan tradicionalmente a sus tierras y territorios y, por ende, generan que sus planes de vida propios se vean modificados o sean imposibles de realizar.

\section{Conclusión}

El resultado al que arribo, en consonancia con lo que fue planteado al inicio del presente trabajo y con lo que fue oportunamente desarrollado, es al de confirmar la hipótesis propuesta como sustento del trabajo. En tanto, es de mi consideración que la incompatibilidad que existe entre un sistema de producción que se funda en la sobre-explotación de los recursos y en el avance indiscriminado de las fronteras de producción, dando preferencia al sector inversionista privado, no puede ser compatible con el respeto a la identidad cultural y a la cosmovisión indígena sobre el valor de la tierra. La utilización no sustentable de la tierra y el consecuente desplazamiento de comunidades indígeno-campesinas de sus territorios ancestrales no hace más que validar mi postura, en razón de que implica la aniquilación de las posibilidades que estos pueblos tienen de subsistir culturalmente y también porque un modelo económico y de producción no puede basarse en presupuestos violatorios de derechos humanos.

\footnotetext{
${ }^{148} \mathrm{CIDH}$. Audiencia sobre la situación de derechos humanos de las personas afectadas por las industrias extractivas en las Américas, 144 Período de Sesiones, 28 de marzo de 2012. ${ }^{149} \mathrm{CIDH}$. Audiencia sobre la situación de derechos humanos de las personas afectadas por las industrias extractivas en las Américas, 144 Período de Sesiones, 28 de marzo de 2012.
} 
La subsistencia de la identidad cultural de los pueblos indígenas, como se ha demostrado a la largo del desarrollo del presente, implica una relación simbiótica con la tierra. La posesión y el uso y goce de la tierra, no sólo garantizan la subsistencia de las comunidades en tanto cubren sus necesidades básicas de alimentación y salud, sino que preserva la idiosincrasia de los pueblos, cuya vida comunitaria se desarrolla y gira en torno a la tierra.

Pero no es la privación de la posesión de la tierra el único elemento cuestionable, hemos podido apreciar como los Estados pueden violar de diversas formas los derechos de los pueblos indígenas y amenazar su continuidad cultural. Toda vez que se prive del ejercicio de las formas de vida que los pueblos históricamente han realizado; cada vez que se autorice un emprendimiento de explotación que implica la modificación de los ecosistemas adyacentes, la contaminación de las aguas, la pérdida de la biodiversidad; se estará propiciando otro elemento violatorio de los derechos humanos de los pueblos originarios.

Un modelo productivo que de hecho implica la sobre-explotación de los recursos y la deforestación de estos territorios ancestrales como medio de satisfacción de la demanda de productividad para la exportación de bienes primarios, entre otros aspectos, no constituye un modelo de "desarrollo". Implica, de otra forma, un avasallamiento de derechos constitucionalmente garantizados a estos pueblos indígenas.

La necesidad de visualizar y dar entidad a un fenómeno invisibilizado, como es el que opera la lógica neoextractivista, es de suma importancia para la salvaguarda del estado de derecho en Argentina y en los países del sistema interamericano en general. Cuando se otorga entidad a una problemática, esta resurge a la superficie de la realidad política y social de un momento histórico. Allí es donde reside la importancia de lo que acontece, en trasladarlo al plano de la visibilidad. En Argentina y en América Latina se suceden trasgresiones a los estándares de derechos humanos toda vez que en nombre del "desarrollo" 
y el "progreso" de la supuesta sociedad entera, se construye un sistema económico-productivo que se desarrolla a expensas de una minoría históricamente relegada y acallada.

\section{Bibliografía}

Gialdino, Rolando E.; "El rescate de la diferencia. Las comunidades indígenas en la jurisprudencia de la Corte Interamericana de Derechos Humanos"; Ed. La Ley; Fuente: JA 2006 III 1178; Suplemento de Jurisprudencia Argentina; 6/9/2006.

Anaya, James; "Informe del Relator Especial sobre los derechos de los pueblos indígenas, James Anaya. Observaciones sobre la situación de los derechos de los pueblos indígenas de Guatemala en relación con los proyectos extractivos, y otro tipo de proyectos, en sus territorios tradicionales"; ONU, Consejo de Derechos Humanos $18 .^{\circ}$ período de sesiones Tema 3 de la agenda Promoción y protección de todos los derechos humanos, civiles, políticos, económicos, sociales y culturales incluido el derecho al desarrollo; Distr. general 7 de junio de 2011; Disponible en: https://www.ohchr.org/Documents/ Issues/IPeoples/SR/A-HRC-18-35-Add-3_sp.pdf

Comisión Interamericana de Derechos Humanos; "Derechos de los Pueblos Indígenas y Tribales sobre sus tierras ancestrales y recursos naturales. Normas y Jurisprudencia del Sistema Interamericano de Derechos Humanos"; OEA/Ser.L/V/II.; Doc. 56/09; 30 diciembre 2009. Disponible en: http://www.oas.org/ es/cidh/indigenas/docs/pdf/Tierras-Ancestrales.ESP.pdf

Comisión Interamericana de Derechos Humanos; "La situación de los Derechos Humanos de los Indígenas en las Américas"; OEA/Ser.L/VII.108 Doc. 62; 20 octubre 2000; Disponible en: http://www.cidh.org/Indigenas/indice.htm

Comisión Interamericana de Derechos Humanos; "Pueblos indígenas, comunidades afrodescendientes y recursos naturales: protección de derechos humanos en el contexto de actividades de extracción, explotación y desarrollo"; OEA/Ser.L/V/II. Doc. 47/15 31 diciembre 2015; Disponible en: http://www.oas.org/ es/cidh/informes/pdfs/IndustriasExtractivas2016.pdf 
Comisión Interamericana de Derechos Humanos; "Cuadernillo de Jurisprudencia de la Corte Interamericana de Derechos Humanos $\mathrm{N}^{\circ}$ 11. PUEBLOS INDÍGENAS Y TRIBALES"; Disponible en: http://www.corteidh.or.cr/sitios/libros/todos/docs/indigenas.pdf

Maristella Svampa; Enrique Viale Trazar; "Continuidad y radicalización del neoextractivismo en Argentina"; Perfiles Económicos No3, Julio 2017.

Maristella Svampa; "El Consenso de los Commodities. Extractivismo en América Latina"; Le Monde Diplomatique, edición Cono Sur; Edición de Junio de 2013/ N. ${ }^{\circ}$ 168. Disponible en: https://www.eldiplo.org/la-trampa-de-los-recursos-naturales/ el-consenso-de-los-commodities/

Darío Aranda; "Los desplazados por la soja y la minería"; Página 12, Buenos Aires, 22 de febrero de 2010. Disponible en: https:// www.pagina12.com.ar/diario/elpais/1-140779-2010-02-22. html

Dario Aranda; "Tierra Arrasada. Petróleo, soja, pasteras y megaminería. Radiografía de la Argentina del Siglo XXI"; Sudamericana; Buenos Aires; 2015.

Lander, Edgardo; "El Neoextractivismo como modelo de desarrollo en América Latina y sus contradicciones"; Heinrich Böll Stiftung, Berlín, 13-14 de mayo de 2014; Disponible en: https:// mx.boell.org/sites/default/files/edgardolander.pdf

Svampa, Maristella 2012 "Consenso de los commodities, giro ecoterritorial y pensamiento crítico en América Latina" en OSAL (Buenos Aires: CLACSO) Año XIII, N ${ }^{\circ}$ 32, noviembre. Disponible en: http://biblioteca.clacso.edu.ar/clacso/ osal/20120927103642/OSAL32.pdf 